\section{LA ESPIRAL IRRESISTIBLE: \\ LA GRAN GUERRA $Y$ \\ EL PROTECTORADO ESPAÑOL EN MARRUECOS}

\section{An irresistible spiral: the Great War and the Spanish Protectorate in Morocco}

\author{
Pablo La Porte \\ Heriot-Waltt University - Edinburgh \\ P.La Porte@hw.ac.uk
}

Recibido: 08-/06/2016 - Aceptado: 20/10/2016

Cómo citar este artículo/Citation:

Pablo LA PORTE (2017), "La espiral irresistible: la Gran Guerra y el Protectorado español en Marruecos", Hispania Nova, 15, págs. 500-526,

DOI: https://doi.org/10.20318/hn.2017.3499
Copyright: (c) HISPANIA NOVA es una revista debidamente registrada, con ISSN 1138-7319 y Depósito Legal M 9472-1998. Los textos publicados en esta revista están -si no se indica lo contrario- bajo una licencia Reconocimiento-Sin obras derivadas 3.0 España de Creative Commons. Puede copiarlos, distribuirlos y comunicarlos públicamente siempre que cite su autor y la revista y la institución que los publica y no haga con ellos obras derivadas. La licencia completa se puede consultar en: http://creativecommons.org/licenses/by-nd/3.0/es/deed.es
Resumen: Se arguye en estas páginas que la Primera Guerra Mundial tuvo una influencia significativa y difícil de ignorar en el Protectorado español en Marruecos, donde contribuyó a alimentar contradicciones y conflictos que pasarían a formar parte de la idiosincrasia de la aventura colonial española —divisiones entre germanófilos y aliadófilos en la oficialidad del ejército colonial, tensiones entre las autoridades españolas y las autoridades coloniales francesas como consecuencia de las mismas, resistencias locales fomentadas por agentes alemanes-. Todas estas fricciones dificultarían aún más la labor de los últimos gobiernos de la Restauración y gravitarían de manera destacada en la crisis final del régimen (1918-1923).

Palabras clave: Marruecos, Protectorado español, Primera Guerra Mundial, Ejército de África africanistas.
Abstract: This article argues that the repercussions of the First World War in the Spanish Protectorate in Morocco, often overlooked in the literature, were far from negligible. Tensions within the Spanish Army of Africa resurfaced and relations with French counterparts in Morocco steadily deteriorated as a result of the conflict. Ultimately, the Great War highlighted (and aggravated) the contradictions, problems and denials of the Spanish colonisation in Morocco. After the war, all the conditions were present for the transformation of the Moroccan venture in the most formidable challenge that the Spanish governments were to face in the last years of the Restoration regime (1918-1923).

Keywords: Morocco, Spanish Protectorate, First World War, Army of Africa, africanists. 


\section{LA ESPIRAL IRRESISTIBLE:}

\section{LA GRAN GUERRA Y EL PROTECTORADO ESPAÑOL EN MARRUECOS}

La cada vez más extensa bibliografía sobre la Primera Guerra Mundial, a la que estas páginas contribuirán inevitablemente, ha destacado recientemente algunos rasgos distintivos y perfiles particulares de las potencias que se mantuvieron neutrales durante el conflicto, que tienen un interés indudable y que pueden servir para introducir este artículo ${ }^{1}$. En lo concerniente a la situación en la Península, se ha mencionado en diversas ocasiones y en otras partes de este libro la idea de que la Gran Guerra produjo en España una división profunda y apasionada entre germanófilos y aliadófilos, que polarizó a la opinión pública y que configuró un fenómeno en buena medida desconocido en otras naciones no beligerantes (Suiza, Holanda o Suecia), menos proclives o ajenas a esta radicalización. Esta "guerra ideológica" fue particularmente enconada e intensa en España no porque respondiera con mayor vigor que en otros países europeos a las diversas etapas de la guerra, sino porque, según esta interpretación, reflejaba un conflicto doméstico de una larga tradición y calado histórico: el enfrentamiento entre la España tradicional, conservadora y católica y la España progresista, liberal y laica, que habían comenzado a navegar cursos irreconciliables desde los comienzos de la Revolución Francesa. Esta atractiva visión, que ha situado la controversia de la Gran Guerra en el curso latente de la división entre "las dos Españas", explicaría así convincentemente la vehemencia y el apasionamiento del debate entre germanófilos y aliadófilos, admitiendo que la inmensa mayoría de la población española probablemente ni participara en dicho debate ni se viera afectada por el mismo ${ }^{2}$.

\footnotetext{
${ }^{1}$ La escasa atención que tradicionalmente han recibido las potencias neutrales durante el conflicto está siendo hoy progresivamente superada. Véase, por ejemplo, Herman AMERSFOORT y Wim KLINKERT (eds.), Small Powers in the Age of Total War, 1900-1940. Leiden, BRILL, 2010; Johan DEN HERTOG y Samuël KRUIZINGA (eds.), Caught in the Middle: Neutrals, Neutrality, and the First World War. Amsterdam, Amsterdam University Press, 2011; y Maartje ABBENHUIS, An Age of Neutrals: Great Power Politics, 1815-1914. Cambridge, CUP, 2015.

2 Esta interpretación fue presentada hace ya unos años por Gerald H. MEAKER, "A Civil War of Words: The Ideological Impact of the First World War on Spain, 1914-18", en Hans A. SCHMITT (ed.), Neutral Europe Between War and Revolution, 1917-23. Charlottesville, Univ. of Virginia Press, 1988, pp. 2-6. Recientemente, ha sido recuperada por Francisco ROMERO SALVADÓ, Spain 1914-1918: Between War and Revolution. Londres, Routledge, 1999, pp. 8-10, Javier KRAUEL, "Visión parcial del enemigo íntimo: la Gran Guerra como antesala de la Guerra Civil", Vanderbilt e-Journal of Luso-Hispanic Studies, 5/1 (2009), pp. 157-160 y Javier PONCE, "Under Propaganda Fire: Spain and the Great War", en María Fernanda ROLLO, Ana Paula PIRES y Noémia Malva NOVAIS (eds.), War and Propaganda in the XXth Century. Lisboa, IHC, 2013, p. 13. Otros autores han cuestionado, sin embargo, la pretendida singularidad y excepcionalidad del caso español. Véase Maximiliano FUENTES CODERA, "Más allá de aliadófilos y germanófilos: trayectorias europeístas y pacifistas durante la Gran Guerra en España", Dimensioni e problemi della ricerca storica, 1 (2015), pp. 131-148.
} 
Otros aspectos particulares y distintivos del caso español —aún escasamente representado en la historiografía del conflicto, según consenso general ${ }^{3}$ — han pasado hasta cierto punto desapercibidos para los historiadores. Entre ellos destaca la presencia de España en un entorno colonial cercano y próximo al conflicto continental, en el que la Gran Guerra se manifestó de diversos modos y en diversos grados. El Protectorado de España en Marruecos (o, por mejor decir, la Zona de influencia de España en Marruecos, establecida por el Tratado franco-español de 1912), añade así una dimensión singular a las circunstancias que atravesó España durante la Primera Guerra Mundial, cuyo interés sobrepasa el estricto carácter colonial —otras potencias neutrales, como Holanda, también disponían de territorios coloniales - y adquiere una importancia intrínseca por su proximidad geográfica al escenario bélico y por las reverberaciones del mismo en la zona española. La atención a la presencia de España más allá del Estrecho, por tanto, puede servir así para enriquecer el estudio de los años de la Gran Guerra y evaluar más precisamente sus repercusiones en la política marroquí y peninsular ${ }^{4}$.

Puede decirse que Marruecos acabaría, de algún modo y de manera figurada, catapultándose desde las costas de África hasta el mismo centro peninsular, donde aterrizaría, por así decir, en las controversias entre germanófilos y aliadófilos y entre junteros y africanistas, polémicas que se entrecruzaron e influyeron recíprocamente. La misión colonial de España en el norte de África pasó así a integrarse y a formar parte de estas disputas, y sirvió tanto para apoyar puntos de vista diversos con respecto a la guerra (e incluso anhelos pacifistas), como para ilustrar los inveterados problemas de la organización militar en España (corrupción, ineficacia, carencia de recursos) ${ }^{5}$. Lejos de ser una cuestión añadida y marginal, su preeminencia en el debate público peninsular durante los años de la guerra acabaría sacudiendo los propios cimientos y las mismas bases de la acción colonial en Marruecos, devolviendo finalmente al otro lado del Estrecho un modelo de actuación transformado y significativamente distinto — sobre todo tras las reformas militares del gobierno Maura de 1918-, que, a partir de entonces, caracterizaría a la administración española. El escenario colonial reflejaría además otras divisiones y convulsiones sociales experimentadas en la Península durante la guerra — sobre todo las del verano revolucionario de 1917-, si bien de manera menos intensa.

Como quizás podía preverse, por otra parte, la zona de influencia de España en Marruecos pasó a incluirse en los cálculos y estrategias de las potencias beligerantes, y pronto se convirtió en un escenario adicional de las intrigas continentales. En él se representaron, por un lado, estrategias, promesas de rebelión, pagos y sobornos, envíos de municiones y armamento y levantamientos

\footnotetext{
${ }^{3}$ Como señala, entre otros, Rosa PARDO SANZ, “España ante el conflicto bélico de 1914-1918: ¿una espléndida neutralidad?", en Salvador FORNER (ed.), Coyuntura internacional y política española (1898-2004). Madrid, Biblioteca Nueva, 2010, pp. 45-63.

${ }^{4}$ No es casual la creciente atención que han despertado los imperios coloniales en los estudios recientes sobre la Primera Guerra Mundial. Véase, por ejemplo, Santanu DAS (ed.), Race, Empire and First World War Writing. Cambridge, CUP, 2011; Robert GERWARTH y Erez MANELA (eds.), Empires at War: 1911-1923. Oxford, OUP, 2014 y Andrew TAIT JARBOE y Richard S. FOGARTY (eds.), Empires in World War I: Shifting Frontiers and Imperial Dynamics in a Global Context. Londres, I.B. Tauris, 2014. Algunos autores han destacado también la relativa atención en estos estudios a la presencia de España en Marruecos. Recientemente, Fernando GARCíA SANZ, España en la Gran Guerra: espías, diplomáticos y traficantes. Barcelona, Galaxia Gutenberg, 2014, pp. 23-25.

${ }^{5}$ Ello ofreció a la opinión pública española (o, al menos, a parte de la misma), una nueva oportunidad para cuestionar las prioridades y objetivos de la política colonial en África, tras los acontecimientos de 1909. Véase Andrée BACHOUD, Los españoles ante las campañas de Marruecos. Madrid, Espasa-Calpe, 1988, pp. 163-164 y Sebastian BALFOUR, The End of the Spanish Empire, 1898-1923. Oxford, OUP, 1997, pp. 200-204.
}

HISPANIA NOVA., 15 (2017), págs. 500-526 DOI: https://doi.org/10.20318/hn.2017.3499 
puntuales, alimentados por las aspiraciones alemanas de provocar una sublevación general en el mundo musulmán en contra las potencias de la Entente. Por otra parte, la zona española recibiría también la atención dedicada y particular de los servicios de inteligencia colonial franceses, verdaderamente inquietos por la posibilidad de una rebelión local que comprometiera su cada vez más expuesta situación en Marruecos. En dicha situación de ansiedad e incertidumbre, la actitud ambigua de las autoridades coloniales españolas con respecto a las actividades de los agentes alemanes avivaría temores de posibles agitaciones y disturbios, en lugar de disiparlos. Es bien conocido que la insurrección general que pretendían provocar los agentes alemanes en Marruecos no fructificó finalmente, algo que no debería servir, sin embargo, para disminuir su importancia —particularmente, a los ojos de la inteligencia militar francesa-, o para ignorar los perjuicios que se derivaron de la misma para el futuro de la acción española en Marruecos ${ }^{6}$.

Este artículo analiza brevemente estas dos dimensiones principales de la guerra europea en la zona de influencia de España en Marruecos. La interpretación que ofrece es relativamente simple y podría resumirse así: el torbellino de la guerra europea atrajo de manera inevitable la acción colonial de España en Marruecos al centro del debate público, de las discusiones, enfrentamientos y conflictos que se manifestaron en aquellos años en la opinión peninsular. A lo largo de este proceso, la estrategia colonial de España en Marruecos se vio cuestionada, discutida y finalmente transformada, generándose, por así decir, un nuevo modelo de acción colonial que se trasplantaría al otro lado del Estrecho al final de la guerra. Este nuevo modelo de acción colonizadora, regenerado por las controversias peninsulares, transcurriría a partir de entonces en consonancia con prioridades peninsulares y burocráticas, en mayor medida que de acuerdo a necesidades y exigencias coloniales. Encontraría, además, en la zona española, nuevas condiciones creadas por la guerra y por las actividades de los agentes alemanes, lo que crearía una situación particularmente problemática en los años siguientes ${ }^{7}$.

Traspasando los límites del periodo, se sugiere en estas páginas que las operaciones militares reanudadas en 1919 en ambas zonas del Protectorado español — en la zona oriental de Melilla y la zona occidental de Tetuán — pondrían de manifiesto no sólo las tradicionales e irresueltas carencias del Ejército de África. Evidenciarían también crecientes dificultades para extender el dominio sobre las cabilas de la zona española, derivadas tanto de los anhelos despertados por las promesas alemanas durante la guerra, como de la actitud adoptada por la administración francesa en vista de la tibia respuesta de las autoridades españolas ante las mismas. Puede resultar aventurado insinuar que los episodios que tuvieron lugar en 1921 (el desastre de Annual y el inicio de la guerra del Rif) fueran producto y fruto último de estas contradicciones. Menos arriesgado es constatar que arrojaron una vez

\footnotetext{
${ }^{6}$ Sobre las actividades alemanas y la actitud de las autoridades españolas se citarán posteriormente diversos trabajos. Por el momento, puede mencionarse la extensa obra de Jean-Marc DELAUNAY, Méfiance Cordiale. Les relations franco-espagnoles de la fin du XIXe siècle à la Première Guerre mondiale (Volume 2): Les relations coloniales. París, Editions L'Harmattan, 2011.

${ }^{7}$ No se incluyen en estas páginas referencias a la ciudad de Tánger, excluida del Protectorado español por el Tratado de 1912 y dotada de un régimen especial que aún tardaría años en definirse. La importancia de la ciudad durante el periodo es, sin embargo, indudable. Véase, por ejemplo, Gonzalo TERREROS CEBALLOS, Antonio Maura y la cuestión marroquí. Tesis Doctoral. Madrid, UCM, 2013, pp. 197-203. Desde la perspectiva británica, puede verse John FISHER, British Diplomacy and the Descent into Chaos: The Career of Jack Garnett, 1902-19. Basingstoke, Palgrave Macmillan, 2011, pp. 143-162.
} 
más la cuestión marroquí, esta vez con enorme violencia, al corazón de la debilitada escena peninsular (los últimos impulsos de la Restauración), ayudando a resquebrajarla definitivamente en 1923.

\section{Marruecos en la Península y la Península en Marruecos.}

Habría sido difícil, en realidad, que Marruecos no se convirtiera en una de las cuestiones más debatidas durante los años de la guerra en España. Las apasionadas discusiones y vivos reproches que mantuvieron e intercambiaron aliadófilos y germanófilos en la Península encontraron prontamente en la cuestión colonial argumentos adicionales para apoyar sus posturas, incluyéndola de manera decidida y resuelta en la controversia. Para unos, la presencia de España en Marruecos aparecía como prueba indiscutible de la necesidad de alinear la política exterior española con los objetivos de la Entente y, por tanto, de defender una postura aliadófila. Para otros, la breve experiencia colonial africana había ofrecido ya muestras evidentes de la inquina francesa y la perfidia británica y de los perjuicios derivados de las mismas para los intereses españoles, y debía servir, por tanto, de escarmiento general y demostración de las ventajas de una actitud germanófila. Otras voces más radicales comparecieron también en el debate, presentando Marruecos como un escenario de las intrigas y maquinaciones de todos los poderes europeos, sin excepción alguna y, por tanto, motivo de recelo y sospecha hacia todos ellos $^{8}$. La idea de que la colonización de Marruecos no suponía sino un ejemplo palpable de la creciente arrogancia y beligerancia de las potencias imperiales europeas, que parecía estar conduciendo al continente a una situación sin salida —una interpretación extendida hoy entre los historiadores, al considerar sobre todo las crisis marroquíes de 1905 y 1911—, no llegó a manifestarse de manera clara en el debate público de la época. Probablemente fueran algunos europeístas convencidos, como el escritor Eugenio d'Ors, quienes más se aproximaran a la misma ${ }^{9}$.

El debate militar que se entabló en España desde el inicio de la contienda también incorporó decisivamente la colonización marroquí al centro de la discusión. Como se sabe, la evidencia y el reconocimiento de la impotencia militar del país que, junto con otras razones, sugirió una actitud neutral en el conflicto, no dejó de producir, a la vez que un cierto alivio en círculos militares cuando esta neutralidad se confirmó oficialmente, tentativas y propuestas de reforma para remediar el estado

\footnotetext{
${ }^{8}$ Los ejemplos del conde de Romanones, el dramaturgo Jacinto Benavente y el científico Santiago Ramón y Cajal pueden servir para ilustrar estas tres posturas, respectivamente (Fernando DíAZ-PLAJA, Francófilos y germanófilos: los españoles en la guerra europea. Barcelona, DOPESA, 1973, pp.17-67). Las obras que recorren las divisiones entre aliadófilos y germanófilos durante la guerra son muy numerosas y se recogen en otros artículos de este volumen. Entre las que destacan el papel de Marruecos en el debate, pueden mencionarse Carolyn P. BOYD, Praetorian Politics in Liberal Spain. Chapel Hill, University of North Carolina Press, 1979, pp. 45 y ss. y Gerald H. MEAKER, op. cit., pp. 10-32. Este último autor ha señalado que la cuestión de Marruecos condensó las divisiones entre las naturales e instintivas tendencias germanófilas y la razón de Estado defendida por los aliadófilos (op. cit., p. 11). Versiones recientes de la cuestión en Gonzalo TERREROS CEBALLOS, op. cit., pp. 205-218; Javier PONCE, "Propaganda and Politics: Germany and Spanish Opinion in World War I", en Troy R.E. PADDOCK (ed.), World War I and Propaganda. Boston, BRILL, 2014, pp. 292-321; y Maximiliano FUENTES CODERA, España en La Primera Guerra Mundial. Una movilización cultural. Madrid, Akal, 2014, pp. 129 y ss.

${ }^{9}$ Aunque, desde luego, desde una distancia considerable. Véase Maximiliano FUENTES CODERA, "La particular dimensión europea de Eugeni d'Ors durante la Primera Guerra Mundial”, Ayer, 76 (2009), pp. 209-243.
}

HISPANIA NOVA., 15 (2017), págs. 500-526 DOI: https://doi.org/10.20318/hn.2017.3499 
precario del Ejército español, aún más evidente al compararlo con otros pujantes ejércitos europeos ${ }^{10}$. Se convirtió entonces en verdad aceptada la idea de que la institución militar en España necesitaba de una regeneración profunda, frecuentemente referida al aligeramiento de las escalas, a la reducción del número de oficiales, a una mejora de sus elementos técnicos y a una nueva mentalidad operativa. Los males históricos del Ejército español, heredados del turbulento siglo XIX, se habían hecho particularmente presentes en vísperas de la conflagración entre la Triple Alianza y la Triple Entente, y a ellos, o así se pensaba al menos en círculos políticos y militares, era necesario poner fin de manera tajante ${ }^{11}$.

Dentro de este contexto innovador y regeneracionista, que se explora mejor en otras partes de este volumen, Marruecos acabó perfilándose como un elemento descollante, sobre todo por su vinculación con proyectos de reforma presentados en las Cortes que incluían disposiciones sobre el personal militar. El ejemplo de las campañas de 1909 y, en menor medida, de las operaciones del río Kert en 1911 y 1912 — todas ellas en los alrededores de Melilla—, durante las cuales se habían concedido en abundancia ascensos y condecoraciones por méritos de guerra, sirvieron de preámbulo a otras propuestas para facilitar el paso a la reserva en las escalas superiores del Ejército y a otras iniciativas para agilizar y mejorar la operatividad y eficacia de sus unidades ${ }^{12}$.

Por supuesto, estos intentos de reforma, simbolizados quizás de manera eminente por los proyectos del ministro de Guerra del gobierno Romanones, el general Luque, en 1916, encontraron enorme resistencia en algunos sectores del ejército - lo que se ha convenido en llamar la opinión "juntera" - que se revistió inmediatamente de un lenguaje igualmente regeneracionista para oponerse a sus extremos y finalmente frustrarlos ${ }^{13}$. Se han tratado en otros artículos de este volumen los efectos y consecuencias que esta reacción tuvo para las relaciones entre el poder civil y el poder militar en España, ya de por sí enrarecidas desde comienzos de siglo. Baste mencionar aquí que, al igual que

\footnotetext{
${ }^{10}$ La impotencia militar de España al inicio del conflicto es uno de los pocos puntos en el que parecen estar de acuerdo los historiadores. Véase José Antonio MONTERO JIMÉNEZ, “España y los Estados Unidos frente a la Primera Guerra Mundial", Historia y Política, 32 (2014), p. 73-74.

${ }^{11}$ Pueden encontrarse interesante estudios sobre la influencia del Protectorado marroquí en la mentalidad militar tras el desastre de 1898 en Sebastian BALFOUR, "The Making of an Interventionist Army, 1898-1923", en Francisco J. ROMERO SALVADÓ y Angel SMITH (eds.), The Agony of Spanish Liberalism. From Revolution to Dictatorship, 1913-1923. Basingstoke, Palgrave Macmillan, 2010, pp. 255-274; y en Geoffrey JENSEN, "Moral strength through material defeat? The consequences of 1898 for Spanish military culture", War \& Society, 17 (1999), pp. 25-39. Existe también cierta coincidencia entre historiadores en lo que se refiere a la aparente inevitabilidad de una reforma militar en España, una vez había comenzado la guerra y se había confirmado oficialmente la neutralidad del país. Entre otros, Stanley G. PAYNE, Politics and the Military in Modern Spain. Stanford, CA., Stanford University Press, 1967, pp. 123-128; Carolyn P. BOYD, op. cit., pp. 28-42; y, más recientemente, Javier PONCE, "World War I: Unarmed Neutrality", en Wayne H. BOWER y José E. ÁLVAREZ, A Military History of Modern Spain. Westport, Praeger, 2007, pp. 62-64.

12 Los ascensos por méritos de guerra habían sido eliminados tras los abusos ocurridos en Cuba, pero fueron reintroducidos el ministro de Guerra del gobierno Canalejas, el general Luque, en 1910, y abundantemente otorgados tras las campañas de 1909. Véase Stanley G. PAYNE, op. cit., p. 123; Carolyn P. BOYD, op. cit., p. 41; y Antonio ATIENZA PEÑARROCHA, Africanistas y Junteros: el Ejército español en África y el oficial José Enrique Varela Iglesias. Tesis Doctoral. Valencia, Alfara, 2012, pp. 237-240.

${ }^{13}$ Sobre las fallidas reformas del general Echagüe en 1914 y del general Luque en 1915 y 1916, puede verse Stanley G. PAYNE, op. cit., pp. 123-151; Carolyn P. BOYD, op. cit., pp. 44-59 y, más recientemente, Antonio ATIENZA PEÑARROCHA, op. cit., pp. 233-236.
} 
ocurrió en el debate entre aliadófilos y germanófilos, Marruecos pasó a convertirse en una cuestión central en las divisiones en el seno del ejército, que a partir de entonces se identificarían con las corrientes "juntera" y "africanista" ${ }^{14}$.

Las pasiones creadas por estos debates en España remitieron y se difuminaron al atravesar el Estrecho. En primer lugar, la polémica entre aliadófilos y germanófilos tuvo efectos mucho más mitigados en el Protectorado español que en la Península. Admitiendo las dificultades para conocer de manera precisa cómo desembocaron los extremos de este debate en la zona de influencia española en Marruecos, sí parece posible concluir que éste no tuvo el alcance ni la resonancia que adquirió en los medios de opinión peninsular. Algunos historiadores han explicado esta situación refiriéndose a circunstancias y factores que explicarían esta relativa quietud y pasividad. En primer lugar, el papel dominante del Ejército tanto en las plazas de soberanía (Ceuta y Melilla) como en territorio de Protectorado —donde, de manera más intensa que en la Península, Francia era percibida como el enemigo-, pareció asegurar una indiscutida y predominante opinión germanófila ${ }^{15}$. La escasa población española en el Protectorado, por otra parte, distribuida de manera muy desigual, dispersa por todo el territorio y compuesta en buena parte por braceros y agricultores que buscaban alivio a las penurias de la vida rural en Andalucía, Extremadura y Valencia, estaba lejos de ser una audiencia receptiva a estas disquisiciones y polémicas peninsulares ${ }^{16}$. Sus condiciones de vida, muy similares a las de la población local y en estrecho contacto con la misma, por lo que sugieren los testimonios de la época, parecían estar dominadas por preocupaciones más acuciantes relacionadas con el sustento diario. En situaciones cercanas a la miseria y muy afectadas por el analfabetismo, las posibles implicaciones de un alineamiento de la política exterior española en un sentido aliadófilo o germanófilo no parecieron suscitar excesivos entusiasmos ni interés ${ }^{17}$. Aún más evidente resultó esta relativa indiferencia entre las tribus situadas dentro de los límites de la zona española, para quienes la cuestión

14 De manera resumida, puede decirse que los" junteros", la mayoría de ellos destinados en la península, rechazaban los ascensos por méritos de guerra y defendían los ascensos por estricta antigüedad. Los "africanistas", por el contrario, se encontraban en su mayoría entre la oficialidad de las fuerzas de choque del Ejército de África y eran partidarios de los ascensos por méritos de guerra. Véase Carolyn P. BOYD, op. cit. pp. 2842. El lugar central de Marruecos en las disputas entre "junteros" y "africanistas" en Sebastian BALFOUR, The Making..., p. 263.

${ }^{15}$ Francisco ROMERO SALVADÓ, Spain..., pp. 85 y ss. Las cifras varían, pero puede decirse que las guarniciones militares —unos 20.000 soldados en Ceuta y otros tantos en Melilla en 1914 - constituían aproximadamente la mitad de la población total en las plazas de soberanía. Por su parte, en Tetuán había 3.000 civiles y casi 14.000 militares a comienzos de 1915. Véase Bernabé LÓPEZ GARCÍA, "España en Marruecos. Demografía de una historia compartida", en Oumama AOUAD y Fatiha BENLABBAH (coords.), Españoles en Marruecos, 1900-2007. Historia y memoria popular de una convivencia. Rabat, Bouregreg, 2007, pp. 17-32.

${ }^{16}$ Manuela MARíN, Testigos coloniales españoles en Marruecos (1860-1956). Barcelona, Bellaterra, 2015, pp. 5561. Las cifras apuntan a unos 10.000-15.000 españoles en el Protectorado al comienzo de la guerra, sin contar los contingentes militares. Véase también Bernabé LÓPEZ GARCÍA, “Aportación a la historia demográfica del Magreb del siglo XX: los españoles en Marruecos", en Manuel ARAGÓN REYES (dir.), El Protectorado español en Marruecos: la historia trascendida. Bilbao, Iberdrola, vol. I, 2013, p. 214.

${ }^{17}$ Véase Sergio BARCE, "La vida cotidiana durante el Protectorado en la ciudad de Larache” y Mohamed Dahiri, “La emigración española a Marruecos: 1836-1956”, ambos en Manuel ARAGÓN REYES, op. cit., vol. I, pp. 149-173 y pp. 175-196, respectivamente. 
fundamental durante los años de la guerra estuvo relacionada sobre todo con las intrigas de los agentes alemanes y los beneficios o perjuicios que podían derivarse de las mismas ${ }^{18}$.

En lo que se refiere a la población urbana, que por entonces comenzaba a congregarse en las ciudades de Tetuán y Larache, puede decirse que existían también condiciones que limitaban las posibles reverberaciones del debate germanófilo-aliadófilo. La difusión de la prensa escrita, por ejemplo, adolecía de falta de recursos, a la que se sumaba la escasez de diarios peninsulares que atravesaban el Estrecho o se divulgaban más allá de las plazas de soberanía de Ceuta y Melilla. La prensa publicada en el Protectorado, por su parte, además de su reducido número de ejemplares (y la dependencia estrecha de las subvenciones oficiales para la impresión de los mismos), apenas traspasaba los límites de la capital del Protectorado y de Larache ${ }^{19}$. A ello se añadía la vigilancia y censura militar, predominante en todo el territorio, que condicionaba también los contenidos de la prensa y sus posibles fluctuaciones ideológicas, particularmente desde la aprobación de las instrucciones del Alto Comisario, el general Gómez Jordana (1915-1918), para el ejercicio de la censura previa en 1916. Estos factores parecen apoyar la impresión de un impacto muy reducido de las polémicas peninsulares en el ámbito colonial, derivado tanto de la reducida presencia y circulación de la prensa como de las restricciones impuestas a la misma ${ }^{20}$.

Las divisiones entre "junteros" y "africanistas" se reprodujeron también al otro lado del Estrecho, en este caso con mayor vigor que las discusiones sobre la actitud de España durante la guerra. Hay motivos para sospechar, sin embargo, que existían circunstancias que atemperaban igualmente esta disputa, según han hecho notar diversos historiadores ${ }^{21}$. La inflación generalizada de precios que acompañó a los años de la guerra —uno de los agravios fundamentales de los oficiales y suboficiales estacionados en la Península y motivo principal de resentimiento contra las recompensas y ascensos por méritos de guerra - afectó en menor medida a los mandos destinados en la Zona de influencia española, que recibían suplementos en sus pagas y que tenían a su disposición productos y servicios a precios más baratos que en la Península (aunque fueran más reducidos $y$, probablemente, de inferior calidad). Ello se veía acompañado por la corrupción dominante y por la proliferación de negocios

18 La suerte final de la guerra (y la esperanza de una derrota francesa) parecieron ser las principales preocupaciones entre las tribus de la zona española. Véase Mimoun AZIZA, "La sociedad marroquí bajo el Protectorado español, 1912-1956", en Manuel ARAGÓN REYES, op. cit., pp. 127-136. La población del Protectorado español alcanzaba aproximadamente las 700.000 personas, divididas en unas 60 cabilas.

${ }^{19}$ Existían en el Protectorado español un número limitado de publicaciones periódicas, todas ellas subvencionadas por el Estado y dependientes de la Alta Comisaría española de Marruecos. Entre ellas, se encontraban "El Eco de Tetuán” (1912), “La Correspondencia de África” (Larache, 1914), “El Explorador Rifeño” (Nador, 1915), “El Rincón” (Rincón el Medik, 1917), "Ecos de Arcila” (Arcila, 1918) y “El Norte de África” (Tetuán, 1918). Véase Mustapha ADILA, "Prensa española del protectorado: periodistas y colaboradores", Magriberia: revista anual de investigaciones ibéricas e iberoamericanas, 8 (2013), pp. 275-289. Aportaciones interesantes sobre la prensa en el Protectorado se encuentran también en Cristina BARREIRO GORDILLO, "España y la Gran Guerra a través de la prensa", Aportes, 84 (2014), pp. 161-182.

${ }^{20}$ Las limitadas posibilidades para llevar a cabo estudios sobre la prensa del Protectorado en estos años han sido suficientemente resaltadas por Mohamed B. BOUNDI, "El ojo del africanismo en Marruecos", Cuadernos de Periodistas, 14 (2008), pp. 93-104 y Mustapha ADILA, "Prensa y periodistas del Protectorado español en Marruecos", en Manuel ARAGÓN REYES, op. cit., vol. II, pp. 155-157.

${ }^{21}$ Entre ellos, Sebastian BALFOUR, Deadly..., pp. 48-49; Carolyn P. BOYD, op. cit., p. 77; y Fernando GARCÍA SANZ, op. cit., p. 45. 
particulares en los que muchos jefes y oficiales se involucraron, que ayudó a paliar situaciones que en España resultaron mucho más severas ${ }^{22}$. La imagen de un ejército mayoritariamente "africanista", sin embargo, tampoco respondía a la realidad de la presencia española en Marruecos. Por una parte, los oficiales "africanistas" constituían una minoría restringida y mayormente circunscrita a las recientemente creadas unidades de Policía Indígena (1909) y de Regulares (1911). Se encontraban, por así decir, rodeados por la presencia numerosa de batallones peninsulares, cuyos mandos estaban afincados en la Península y tan sólo temporalmente destinados en África ${ }^{23}$. Por otra parte, las Juntas de Defensa fueron también activas en Marruecos, donde la pertenencia a las mismas era obligatoria para los oficiales. Se formó así una Junta de Infantería en el Ejército de África, que secundó las demandas de la Junta Central creada en la Península, aunque algunos autores han apuntado que el proceso encontró importantes resistencias ${ }^{24}$. Por lo que se refiere a las Juntas de otras armas del Ejército (Caballería, Artillería, Ingenieros), éstas también contaron con representación colonial. Puede decirse, por tanto, que en el Protectorado español convivían diversas mentalidades y culturas militares, quizás de manera más evidente que en la Península ${ }^{25}$. Ello no fue obstáculo para que, al igual que ocurrió en ciudades y guarniciones peninsulares, los órganos de expresión colonial y militar participaran en la disputa entre "junteros" y "africanistas" y fueran seguidos con avidez por la opinión militar, tanto en Ceuta como en Melilla, y también en las principales ciudades del Protectorado ${ }^{26}$.

Igualmente interesante resulta valorar los efectos que las reformas militares que puntuaron los años de la guerra $\rightarrow \mathrm{y}$ que tan claramente manifestaron las carencias del Ejército español al compararlas con la pujanza de otras instituciones militares europeas - tuvieron en la Zona de influencia española en Marruecos. Es apropiado quizás mencionar, inicialmente, que algunos de los más destacados defensores de las reformas militares presentadas a las Cortes (que tan resolutamente rechazarían las Juntas de Defensa) tenían un pasado "africanista" que no fue probablemente ajeno a su postura ${ }^{27}$. Del mismo modo, la reacción "juntera", por así decir, que se produjo en la dirección de las reformas del Ejército a partir de 1917 —probablemente simbolizada de manera más clara en la Ley de Bases de 1918-, devolvió a la estructura y funcionamiento del Ejército de África una dimensión estrictamente "peninsular", en la que las prioridades de las Juntas prevalecieron abrumadoramente

${ }^{22}$ Véase Carolyn P. BOYD, op. cit., p. 40 y Jesús ALBERT SALUEÑA, "La economía del Protectorado español en Marruecos y su coste para España”, en Manual ARAGÓN REYES, op. cit., p. 94. Este último autor también ha señalado que los impuestos que se pagaban en Marruecos eran muy inferiores a los que se pagaban en la Península.

${ }^{23}$ Sebastian BALFOUR, The Making of..., pp. 263-267.

${ }^{24}$ Carolyn P. BOYD, op. cit., p. 60. Las resistencias a las presiones junteras en los regimientos de Infantería del Ejército de África tan sólo se vencieron en 1917, según Boyd.

${ }^{25}$ Véase Sebastian BALFOUR y Pablo LA PORTE, "Spanish Military Cultures and the Moroccan Wars, 1909-36", European History Quarterly, 30/3 (2000), pp. 307-332 y Antonio ATIENZA PEÑARROCHA, op. cit., pp. 272-273. Un recorrido más amplio en Geoffrey JENSEN, Cultura militar española. Modernistas, tradicionalistas y liberales. Madrid, Biblioteca Nueva, 2014.

${ }^{26}$ Sebastian BALFOUR, Deadly..., pp. 48-49. Mientras que “La Correspondencia Militar" defendía los intereses junteros, "El Telegrama del Rif" adoptó la defensa de los africanistas. Boyd señala que también en Marruecos se formaron Juntas de suboficiales (Carolyn P. BOYD, op. cit., p. 77).

${ }^{27}$ El ejemplo del general Luque resulta significativo, dentro de la posición generalizada de las élites militares en contra de las reivindicaciones junteras. Otros generales, como Alfau, Marina o Gómez Jordana también se beneficiaron en sus carreras de ascensos por méritos de guerra (Carolyn P. BOYD, op. cit., p. 94).

HISPANIA NOVA., 15 (2017), págs. 500-526 DOI: https://doi.org/10.20318/hn.2017.3499 
sobre los anhelos africanistas. Numerosos historiadores han coincidido en afirmar que la aplicación de las reformas militares de 1918 al otro lado del Estrecho supuso la victoria de una mentalidad burocrática, funcionarial y quietista, en un escenario en el que esta actitud y disposiciones no respondían a las exigencias y la dinámica de la acción colonial ${ }^{28}$. Ciertamente, y a la vista de los acontecimientos posteriores (campañas de 1919, el desastre de Annual en 1921), hay razones para compartir dicho punto de vista. La relativa tranquilidad de la Zona de influencia española en 1918, sin embargo, es posible que no hiciera presagiar un futuro tan problemático ${ }^{29}$. Del mismo modo, el abuso de los ascensos por méritos de guerra de los años anteriores pareció otorgar a dichas medidas una innegable justificación ${ }^{30}$.

Otros aspectos de la accidentada travesía que vivió la sociedad española en los años de la guerra se dejaron también sentir de manera más mitigada en el teatro marroquí. Las crisis sociales que se produjeron en la Península en estos años, por ejemplo, no encontraron apenas eco ni repercusión más allá del Estrecho ${ }^{31}$. En lo que se refiere a los sucesos del verano de 1917, es cierto que, dejando a un lado la crisis "juntera", las reivindicaciones de la huelga revolucionaria de julio de 1917 y las demandas de la Asamblea de Parlamentarios de Barcelona no dedicaron especial atención a la cuestión colonial. Es posible, como han sugerido algunos autores, que no existieran en España condiciones de inicio verdaderamente propicias para un estallido revolucionario, como las que se podían encontrar en otros países europeos (Alemania, Rusia), y que la neutralidad española en la guerra —es decir, el hecho de que el Ejército español no hubiera sido humillado en el campo de batalla- fuera un factor fundamental para que no se desbordaran las tensiones sociales. Otros elementos como la relativa carestía de la vida (menos grave en 1917 que en años anteriores), la limitada coordinación de las organizaciones sindicales (UGT, CNT) y las estrategias ambiguas de las fuerzas políticas que representaban los intereses de los trabajadores (PSOE), han servido también para explicar la relativa facilidad con la que se dividieron estas fuerzas y con la que el régimen puso fin a la amenaza revolucionaria de 1917. Estos aspectos son igualmente relevantes por lo que se refiere a la situación en Marruecos ${ }^{32}$.

Sin embargo, existen algunas circunstancias relacionadas con las condiciones de vida de los trabajadores españoles en Marruecos que pueden servir también para explicar esta presunta pasividad. Buena parte de los inmigrantes españoles en el Protectorado, como se ha dicho, se dedicaban a tareas agrarias dispersas por el territorio y, por lo general, limitadas a pequeñas explotaciones con una mano de obra reducida (familias, en muchos casos). En los escasos lugares en los que existía una aglomeración señalada de población, como en las ciudades de Tetuán o Larache, los trabajadores llegados desde la

\footnotetext{
${ }^{28}$ Carolyn P. BOYD, op. cit., pp. 94-95; Sebastian BALFOUR, Deadly..., p. 49; Miguel MARTORELL LINARES, José Sánchez-Guerra: un hombre de honor. Madrid. Marcial Pons, 2011, p. 295. Balfour, por ejemplo, señala el efecto "devastador" que la imposición de la escala cerrada produjo en el Ejército de África (op. cit., p. 49). El decreto fue aprobado el 24 de junio de 1918.

${ }^{29}$ Antonio ATIENZA PEÑARROCHA, op. cit., p. 261.

${ }^{30}$ Gonzalo TERREROS CEBALLOS, op. cit., p. 209.

${ }^{31}$ Mimoun AZIZA, op. cit., p. 138; Gonzalo TERREROS CEBALLOS, op. cit., pp. 205-218.

${ }^{32}$ Esta interpretación puede remontarse a Gerald H. MEAKER, op. cit., pp. 43-49. Una revisión reciente de estos argumentos en Miguel MARTORELL LINARES, “«No fue aquello solamente una guerra, fue una revolución»: España y la Primera Guerra Mundial", Historia y Política, 26 (2011), pp. 33-41.
} 
Península se hallaban predominantemente concentrados en el sector artesanal ${ }^{33}$. La explotación minera, quizá la única expresión de interés industrial en el Protectorado, se escalonaba en líneas y rutas tentativas que intentaban comunicar los núcleos urbanos (entiéndase, sobre todo, Melilla) con los yacimientos del interior, a través de reducidos y apartados destacamentos, protegidos por una guarnición militar. La inexistencia de organizaciones agrarias o sindicales que pudieran representar los intereses y coordinar las acciones de los trabajadores españoles, se veía acompañada por la convivencia estrecha de éstos últimos con la mano de obra local, una diferencia entre el Protectorado español y el francés que diversos autores se han preocupado en señalar y que, en su opinión, restó fuerza y cohesión a posibles impulsos revolucionarios ${ }^{34}$. Otros testimonios de la época añaden que muchos de los españoles que se encontraban en el Protectorado habían llegado huyendo de la miseria o las dificultades de la vida en la Península, y que su posible conciencia de clase se había visto inevitablemente afectada por el aislamiento y la dispersión en la búsqueda de oportunidades en una tierra desconocida ${ }^{35}$. No debe olvidarse, por último, la abrumadora presencia militar, evidente en las plazas de soberanía pero también en las ciudades del Protectorado, un elemento no sólo disuasorio sino probablemente terminante en lo relativo a posibles movilizaciones sociales ${ }^{36}$.

\section{UNA NEUTRALIDAD PROBLEMÁTICA.}

Como quizás no podía ser de otro modo, el inicio de la Gran Guerra apremió a los representantes franceses en Marruecos, y, en particular, a su primer Residente General, el mariscal Lyautey - figura colonial por excelencia en la expansión francesa en África-, a requerir de España la introducción de medidas preventivas similares a las establecidas en el Protectorado francés ${ }^{37}$. Ésta postura ante el comienzo del conflicto, no resultaba sorprendente. Revelaba, por el contrario, una interpretación relativamente común de las coordenadas internacionales del Protectorado, que consideraba que la declaración de guerra contra Alemania que había firmado el Sultán a instancias francesas - un temprano triunfo diplomático francés tras la apertura de hostilidades -, se extendía automáticamente a todo el territorio marroquí, y, por tanto, la neutralidad oficial de España en la contienda no regía en las regiones confiadas a su administración en los acuerdos de 1912. Ciertamente, puede decirse que, desde el punto de vista de la legislación internacional, la postura francesa parecía

\footnotetext{
33 En estos años, y de acuerdo con José Fermín BONMATí, en torno al 45\% de los emigrantes españoles a Marruecos eran artesanos y comerciantes, frente a un $27 \%$ de agricultores (Españoles en el Magreb. Siglos XIX y XX. Madrid, Mapfre, 1992, pp. 224-225).

34 Mimoun AZIZA, op. cit., pp. 129-141; Sergio BARCE, op. cit., p. 154; Bernabé LÓPEZ GARCÍA, España en Marruecos..., p. 36. No debe olvidarse, por otra parte, que había en Marruecos exiliados políticos desde finales del siglo XIX, sobre todo anarquistas, que llegaron a fundar un Centro Obrero Internacional en Tánger (Mohamed DAHIRI, op. cit., p. 192).

${ }^{35}$ Mimoun AZIZA, op. cit., p. 129; Mohamed DAHIRI, op. cit., pp. 175-196.

${ }^{36}$ Mimoun AZIZA, op. cit., p. 138; Bernabé LÓPEZ GARCÍA, Aportación..., pp. 209-215.

${ }^{37}$ El propio Lyautey, Residente General de Francia desde el comienzo del protectorado (1912-25), recordaría estas infructuosas iniciativas algunos años después. Maréchal LYAUTEY, "Télégramme a Mr. Pichon, Ministre des Affaires Étrangères", Rabat, 9 de Marzo de 1918. Maroc, 1917-1940, leg. 186. Archives du Ministère des Affaires Étrangères et du Développement International (MAEDI).
} 
estar más que justificada ${ }^{38}$. Más controvertido puede parecer el alineamiento de una potencia inicialmente neutral como Marruecos, un país independiente incluso bajo el régimen de Protectorado, con los objetivos de la política exterior francesa ${ }^{39}$. Una vez superado este obstáculo, sin embargo, resultaba evidente que, siendo el Protectorado una unidad política bajo el gobierno del Sultán, las disposiciones establecidas en el Protectorado francés debían abarcar también la Zona de influencia española.

La neutralidad proclamada por el gobierno de Eduardo Dato (1913-1915), que acabaría prevaleciendo en la Zona española (al menos oficialmente), reveló que, a pesar de la discutible legalidad de la postura española, dichas pretensiones gozaban del tácito apoyo de la diplomacia británica, particularmente deseosa de evitar conflictos entre socios coloniales y de mantener en lo posible el statu quo en el Mediterráneo occidental, sobre todo al comienzo de la guerra. El reacio acomodamiento de la postura francesa ante las prioridades británicas convirtió la zona de influencia de España en Marruecos en un aparente "oasis" de neutralidad en el paisaje de un país oficialmente enemigo de las potencias centrales. Dicha situación, aunque temporalmente satisfactoria para las potencias aliadas, llevaría aparejada sus propias tensiones, derivadas tanto de las futuras actividades de los agentes alemanes como de la reacción de las autoridades españolas ante las mismas ${ }^{40}$.

Por otra parte, la llamada "pacificación" de la zona española, término con el que se justificaba la penetración incruenta en el corazón del territorio, era, sin duda, frágil y vacilante en muchos aspectos. En la región oriental del Protectorado, que abarcaba desde los alrededores de la ciudad de Melilla hasta las inmediaciones de las montañas del Rif, las campañas militares que siguieron al infortunado desastre del Barranco del Lobo (1909) y que continuaron con la toma de posiciones en el río Kert (1911-1912), habían permitido avanzar la presencia del ejército hacia la región central de los dominios españoles. En la zona occidental, el desembarco en Larache en 1911 y la ocupación de Tetuán en 1913 habían permitido similares desarrollos desde la plaza de soberanía de Ceuta, estableciendo también un área aparente de administración y vigilancia española. De las tres Comandancias militares establecidas en Marruecos en 1914, sin embargo, tan sólo la de Larache había alcanzado de manera definitiva el

\footnotetext{
${ }^{38}$ Así lo considera Miguel Hernando de LARRAMENDI MARTínEZ, "El Protectorado de Marruecos y las relaciones internacionales de España (1912-1956)", en Manuel ARAGÓN REYES, op. cit., vol. 3., pp. 100-101.

${ }^{39}$ El Sultán Moulay Youssef (1912-1927), primer sultán de Marruecos bajo el régimen de protectorado, se puso incondicionalmente a disposición de Francia, a pesar del alineamiento del Califato Turco con las Potencias Centrales (Susan G. MILLER, A History of Modern Morocco. Cambridge, CUP, 2013, p. 102).

${ }^{40}$ Javier PONCE MARRERO, "La neutralidad española durante la Primera Guerra Mundial: nuevas perspectivas", en María Encarna NICOLÁS MARÍN y Carmen GONZÁLEZ MARTÍNEZ (coords.), Ayeres en discusión: temas clave de historia contemporánea hoy. Murcia, Servicio de Publicaciones UM, 2009. Disponible en: https://dialnet.unirioja.es/servlet/libro?codigo=399225, fecha de consulta (29/03/2016). Para algunos autores, la actitud española suponía "una violación directa" de los tratados de 1912 (David S. WOOLMAN, Rebels in the Rif: Abd El Krim and the Rif Rebellion, Stanford, SUP, 1968, p. 61), mientras que otros la tildan de "anómala" (Gonzalo CEBALLOS TERREROS, op. cit., p. 194). Resulta tentador considerar esta "victoria" de la diplomacia española como un ejemplo de las ventajas que una vigorosa dinámica exterior puede ofrecer a los estados pequeños que aspiran a mantener su neutralidad en medio de un conflicto general, como señala Efraim KARSH (Neutrality and Small States. New Yok, Routledge, 1988, p. 32). En enero de 1916, España anunció que asumía la representación diplomática de su zona marroquí.
}

HISPANIA NOVA., 15 (2017), págs. 500-526 DOI: https://doi.org/10.20318/hn.2017.3499 
contacto con los límites de la zona francesa, que bordeaba enteramente la zona española por el sur. En la Comandancias de Ceuta y Melilla ésta no era aún una realidad, prohibida por las montañas del Rif ${ }^{41}$.

La fuerza militar estacionada al otro lado del Estrecho al comienzo de la guerra era de unos 75.000 hombres, aproximadamente un $60 \%$ del ejército español, divididos en batallones peninsulares -muchos de ellos en las plazas de soberanía de Ceuta y Melilla y en los que se encuadraban la mayoría de soldados y oficiales - y las unidades de Regulares y Policía Indígena, de más reciente creación y dispersas por todo el territorio del Protectorado ${ }^{42}$. La política que hasta entonces había prevalecido en la acción colonial española, salvo los breves interludios de las campañas militares —en los que se daba a las unidades de Regulares y Policía máximo protagonismo-, había primado lo que se ha dado en llamar "medios de atracción pacífica", basados frecuentemente en pagos efectuados por la administración española a los jefes y notables del territorio, de los que se esperaba una cierta fidelidad o, al menos, una tácita aquiescencia ante la expansión de la influencia española ${ }^{43}$. Estas prácticas, predominantes en todas las Comandancias Generales desde el comienzo de la colonización española, han encontrado desde hace ya algunos años, y de manera escasamente sorprendente, la crítica y la reprobación de los historiadores, que las han descrito frecuentemente como un modelo de actuación ineficaz y costoso, que no aseguraba en ningún caso la tranquilidad en el territorio ni la fidelidad de las tribus a las autoridades españolas ${ }^{44}$. Dichas reservas eran compartidas en muchas ocasiones, y de manera más interesante, por los propios mandos del Ejército de África, cuyas frecuentes vacilaciones y resistencias se acompañaban de advertencias sobre la situación ficticia y profundamente inestable que se podía crear con estas estrategias, cuya suerte parecía depender en últimos término de las veleidades de los jefes de las tribus, en mayor medida que de la eficacia del control español ${ }^{45}$.

Hay algunas consideraciones que pueden hacerse con respecto a esta política y que quizás sea oportuno incluir aquí. En primer lugar, conviene recordar que, más que debida al convencimiento del Alto Comisario español o de los Comandantes Generales de Ceuta o Melilla, la orientación de la estrategia colonial de los primeros años de la colonización española respondía primeramente a las directrices del gobierno peninsular, que quería evitar a toda costa el derramamiento de sangre entre

\footnotetext{
${ }^{41}$ Víctor MORALEZ LEZCANO, El colonialismo hispano-francés en Marruecos, (1898-1927). Madrid, Siglo XXI, 1976. Una reciente exposición en Antonio ATIENZA PEÑARROCHA, op. cit., pp. 201-205.

${ }^{42}$ Andrés CASSINELLO PÉREZ, “EI ejército español en Marruecos. Organización, mandos, tropas y técnica militar", en Manuel ARAGÓN REYES, op. cit., vol. 3., pp. 271-97.

43 Para la cuestión del control de las élites locales véase Josep Lluis MATEO DIESTE, La «hermandad» hispanomarroquí. Política y religión bajo el Protectorado español en Marruecos [1912-1956]. Barcelona, Bellaterra, 2003 y José Luis VILLANOVA VALERO, Los interventores. La piedra angular del Protectorado español en Marruecos. Barcelona, Bellaterra, 2006. Detalles sobre los pagos a jefes locales en C. R. PENNELL, $A$ Country with a Government and a Flag: The Rif War in Morocco, 1921-1926. Wisbech, MENAS Press, 1986, pp. 48-49 y María Rosa DE MADARIAGA, "El papel del Rif en el protectorado: entre la colaboración y la resistencia", en Manuel ARAGÓN REYES, op. cit., vol. III, pp. 75-96.

${ }^{44}$ C. R. PENNELL, Morocco since 1830. A History. London, Hurst and Company, 2000, pp. 180-181; Sebastian BALFOUR, Deadly..., pp. 44-46.

${ }^{45}$ En ocasiones, estas resistencias se revestían de cierto fatalismo, como en el caso del Alto Comisario Francisco Gómez Jordana: "a nadie podemos culpar de los malos trances en que esta carencia de recursos nos coloca", confió al Cte. Gral. de Melilla, Gral. Aizpuru. (Francisco GÓMEZ JORDANA, "Correspondencia con Cte. Gral. de Melilla, Gral. Aizpuru", Tetuán, 30 de Diciembre de 1916. Marruecos. Rollo 739, legajo 2, carpeta 8 . Archivo General Militar de Madrid (AGMM).
} 
tropas peninsulares y la escalada de conflictos que pudieran suponer mayores cargas para el Tesoro nacional. El conde de Romanones, jefe de gobierno en 1913, ofreció en un raro momento de franqueza interesantes reflexiones sobre esta política colonial y sobre sus limitaciones y contradicciones. Dirigiéndose en correspondencia oficial al entonces primer Alto Comisario español, general Alfau, a quien se había encomendado la ocupación de Tetuán en febrero de dicho año, Romanones admitió que su gobierno le había puesto "en un trance de los más difíciles que se puede poner a un hombre" al ordenar que la ocupación de la ciudad se realizara "sin disparar un tiro" ${ }^{46}$. Dejando a un lado el probable deseo de alabar la carrera del general en vísperas de su sustitución —la carta fue escrita como respuesta a la dimisión presentada por el general unas semanas después de la toma de la ciudad—, sí parece evidente que algunos gobernantes conocían las dificultades que estos "medios de atracción pacífica" planteaban a las autoridades españolas en Marruecos ${ }^{47}$.

Los Altos Comisarios de España en Marruecos eran, por otra parte, conscientes de las limitaciones de esta política y, en muchas ocasiones, enemigos de la misma. Quizás el ejemplo más representativo de esta actitud fuera el del propio general Gómez Jordana, Alto Comisario desde julio de 1915 hasta noviembre de 1918, quien, en repetidas ocasiones, manifestó su escasa confianza en estas estrategias de atracción de los jefes locales. En correspondencia con sus superiores en Madrid y también en despachos dirigidos a sus subordinados, Gómez Jordana deploró con frecuencia la inoperancia de estas directrices, debida, en su opinión, tanto al escaso conocimiento de los gobiernos peninsulares sobre la realidad marroquí como a la ineficacia del instrumento a su disposición, el ejército de África, para ponerlas en práctica. En carta dirigida al ministro de Estado, Eduardo Dato, en marzo de 1918, el Alto Comisario expresó sin rodeos su desconfianza hacia estas tácticas, llegando a apuntar a la falta de orientación del gobierno en materia colonial como última explicación de las mismas: "Cuando fui a Madrid para recibir instrucciones" — concluyó con ironía su informe— "tan sólo se me dijo que los dos principios en que se basaba la política del gobierno eran implantar el protectorado en nuestra zona «sin disparar un tiro» $\mathrm{y}$ «sin derramar una gota de sangre $»^{48}$.

Finalmente, puede afirmarse que el pago de subsidios a cambio de la fidelidad de las tribus y cabilas de la zona de influencia española no era muy diferente, como han hecho notar algunos autores, de la práctica e instrucciones que se seguían en amplias regiones del Protectorado francés, donde unas consignas hasta cierto punto similares fueron mucho más exitosas. Más que deplorar la inoperancia inevitable de esta política, por tanto, es interesante también remitirse a la ausencia de otros factores necesarios y adicionales —un proyecto colonial sólido, continuado y coherente por parte del gobierno metropolitano; un instrumento militar competente para ponerlo en práctica; unos servicios de

\footnotetext{
${ }^{46}$ Conde DE ROMANONES, “Correspondencia”, Madrid, 14 de Marzo de 1913. Legajo 6 (2), carpeta 8 (27). Fundación Antonio Maura Montaner (FAMM). De acuerdo con el embajador británico en Madrid, y en lo que se refería a Marruecos, el gobierno estaba "paralizado por el miedo". Arthur H. HARDINGE, Madrid, 3 de Julio de 1914. Morocco, Political Correspondence, Leg. 185/1180. Public Record Office, Foreign Office (PRO FO).

${ }^{47}$ C. R. PENNELL, A Country..., pp. 43-46. En lo relativo a la zona occidental, Balfour afirma que Gómez Jordana hubo de pagar el precio de varias humillaciones por obedecer las instrucciones del gobierno, que quería colaborar a toda costa con el caudillo local, el Raisuni (Sebastian BALFOUR, Deadly..., p. 48).

${ }^{48}$ Francisco GÓMEZ JORDANA, “Correspondencia”, Tetuán, s.f. [1918]. Legajo 304/3. FAMM. C. R. PENNELL concluye que el sistema de pensiones era más una imposición proveniente venía de Madrid que una opción de los Altos Comisarios (C.R. PENNELL, A Country..., p. 53).
} 
información e inteligencia colonial sofisticados y eficaces - para explicar su generalizado fracaso en la zona española ${ }^{49}$.

En lo que se refiere al otro elemento constituyente de la realidad colonial española al otro lado del Estrecho, la población local, puede decirse que su respuesta ante la presencia extranjera - lo que se ha dado en llamar la "tensión" entre las aspiraciones dominadoras de la potencia protectora y las tendencias centrífugas, por así decir, de los habitantes del territorio-, adquirió en el caso español unos caracteres distintivos. Tradicionalmente, conviene recordar, la percepción de las cancillerías europeas sobre la situación social y política de Marruecos se había fundamentado en la existencia de dos áreas diferenciadas, Blad al-Makhzen y Blad al-Siba, que servían para distinguir los territorios en los que la autoridad del Sultán era reconocida y respetada de aquellos en los que no lo era. Dicha dicotomía, al parecer irreversible, se había integrado eficazmente en los discursos y aspiraciones coloniales de finales del siglo XIX para justificar la vigilancia y la necesidad de intervención al otro lado del Estrecho y, posteriormente, para legitimar la presencia de las potencias "protectoras" en el Sultanato, que el Sultán se vio obligado a aceptar definitivamente en $1912^{50}$. De acuerdo con estas categorías, la zona española pertenecía casi en su totalidad al Blad al-Siba (a diferencia de la zona francesa, donde el control y dominio del Sultán se extendía a amplias regiones del territorio). Estos planteamientos podrían servir para explicar por qué la política colonial española pareció asumir muy tempranamente la creencia y la convicción de que su actuación en Marruecos se producía ex novo, es decir, en una suerte de vacío histórico, y en un contexto desvinculado e independiente del resto del Sultanato. De aquí surgiera probablemente el convencimiento de que la acción española no necesitaba realmente ni de la aprobación del Sultán (ignorado en aquellas tierras, según versión oficial), ni de sus supuestos representantes (para muchos meras figuras decorativas, como el Jalifa de la zona española, nombrado en 1913), algo a lo que contribuiría probablemente el deseo de mantener un prurito de independencia con respecto al Protectorado francés ${ }^{51}$. Dicho de otro modo, prevalecieron en los orígenes de la actuación colonial española concepciones eurocéntricas, dicotómicas e interesadas, que tendieron a ignorar la experiencia histórica de ocho siglos de existencia del imperio marroquí, y que simplificaron enormemente el flujo y reflujo de las relaciones entre las comunidades árabe (predominante en Blad alMakhzen) y bereber (predominante en Blad al-Siba), y entre éstas y el Sultán. Subyacía a estas creencias, al mismo tiempo, una cierta ingenuidad y una credulidad generalizada en las posibilidades de

\footnotetext{
${ }^{49}$ Véase Moshe GERSHOVICH, French Military Rule in Morocco. Colonialism and Its Consequences. Oxon, Frank Cass, 2000, pp. 68-69.

${ }^{50}$ Dicha capitulación confirmó también la fase final de un verdadero "cerco diplomático" intensificado por las potencias europeas en la segunda mitad del siglo XIX, que los infructuosos esfuerzos de la diplomacia marroquí no lograron resistir. Véase Thérèse BENJELLOUN, Visages de la diplomatie marocaine depuis 1844. Casablanca, EDDIF, 1991, pp. 43 y ss y, más recientemente, Abdelahad SEBTI, “Colonial experience and territorial Practices", en Driss MAGHRAOUI (ed.), Revisiting the Colonial Past in Morocco. Londres, Routledge, 2013, pp. 38-41. La versión tradicional sobre la decadencia de Marruecos puede verse en Frederick V. PARSONS, The Origins of the Morocco Question (1880-1900), Londres, Duckworth, 1976, particularmente pp. 5-16.

${ }^{51}$ Germain AYACHE mencionó hace ya algunos años estas "ilusiones" sobre las que se fundaba la acción colonial española en Marruecos (Les Origines de la Guerre du Rif. París, Editions de la Sorbonne, 1981, pp. 82-83), también subrayadas por C. R. PENNELL, A Country..., p. 22. Más recientemente, véase Youssef AKMIR, "La historiografía marroquí y la crítica al colonialismo español", en Eloy MARTín CORRALES (ed.), Semana Trágica, Entre las barricadas de Barcelona y el Barranco del Lobo. Barcelona, Bellaterra, 2011, pp. 85-86.
} 
la intervención española, que se suponía que iba a ser capaz de perdurar allí donde la autoridad del Sultán, según consenso generalizado, había naufragado ${ }^{52}$.

Así pues, a esta frágil estructura de dominación militar incipiente, estrategias de atracción política escasamente fiables —afectadas por un desconocimiento general de la geografía, las costumbres, la lengua y modos de vida de sus habitantes - e interpretaciones visionarias e ingenuas sobre la misión de España en Marruecos, vino a sumarse un nuevo y delicado elemento representado por la propaganda y las actividades de los agentes alemanes. Dichas actividades proliferaron desde el comienzo de la Gran Guerra en la zona española (y también en la francesa), y acabarían transformando los vínculos y lazos entre las tribus del territorio, sus contactos con las autoridades españolas y, finalmente, sus relaciones con el Protectorado francés. Es bien sabido que la propaganda alemana, que aspiraba a fomentar la rebelión de las tribus y cabilas de la zona española contra las autoridades del Protectorado francés, formaba parte de un designio mucho más amplio y vasto acariciado por la diplomacia del Káiser — sobre todo desde que se puso de manifiesto que la guerra no iba a resolverse en unos pocos meses, como se había pensado al inicio del conflicto-, que consistía en un levantamiento general del Islam contra la dominación europea, del que se esperaba el colapso de los imperios coloniales de las potencias de la Entente ${ }^{53}$.

La limitada lucidez de estos anhelos de la política exterior alemana y la precaria comprensión de las tensiones latentes en el mundo musulmán han sido detalladas por numerosos autores, y quizás es conveniente revisarlas aquí brevemente. La alianza con el Imperio Otomano, por ejemplo, concretada en agosto de 1914 y de cuyo papel eminente dentro del Islam se esperaba una contribución vital para estos proyectos, pronto mostró sus limitaciones. La idea de que amplios sectores de la comunidad musulmana iban a aceptar y respaldar la llamada a la yihad del Califato turco contra las potencias de la Entente (sobre todo cuando resultaba evidente que era una prioridad fundamentalmente alemana), fue pronto desmentida por la escasa repercusión de estos llamamientos. El liderazgo de las actividades subversivas, del que se adueñaron prontamente los servicios de inteligencia alemanes en Oriente Medio y el norte de África, provocó asimismo una creciente reticencia y distanciamiento entre aquellos llamados a colaborar en esta tarea, además de mostrar reveladoras carencias y un exiguo conocimiento del Islam entre los primeros ${ }^{54}$.

En el caso de Marruecos, estas posibilidades se enfrentaban a otros obstáculos adicionales, que han sido también mencionados por la historiografía. En sus casi ochocientos años de historia como Imperio independiente, por ejemplo, ni la corte imperial ni el Makhzen (ni, por supuesto, el mismo Sultán), habían reconocido la autoridad espiritual del Califato turco. Por el contrario, el Sultán marroquí era venerado como único guía religioso de su pueblo, en su condición de descendiente del Profeta

\footnotetext{
${ }^{52}$ Al mismo tiempo que el carácter demoledor de su propia presencia, como sugiere Germain AYACHE, op. cit., pp. 51-52. Véase también Jonathan WYRTZEN, "Performing the nation in anti-colonial protest in interwar Morocco", Nations and Nationalism, 19 (2013), pp. 621-622 y Abdelahad SEBTI, op. cit., pp. 41-45.

${ }^{53}$ Véase Tilman LÜDKE, Jihad made in Germany. Ottoman and German Propaganda and Intelligence Operations in the First World War. Münster, Lit Verlag, 2005, pp. 56-82.

${ }^{54}$ Véanse, entre otros, Tilman LÜDKE, op. cit., pp.186-203; Sean McMEEKIN, The Berlin-Baghdad Express. The Ottoman Empire and Germany's Bid for World Power. Cambridge MA., Harvard University Press, 2010, pp. 85-139; y Eugene ROGAN, The Fall of the Ottomans. The Great War in the Middle East, 1914-1920. Londres, Penguin, 2015, pp. 53-74.
}

HISPANIA NOVA., 15 (2017), págs. 500-526 DOI: https://doi.org/10.20318/hn.2017.3499 
ungido por voluntad divina. En esta situación, un tanto singular dentro del mundo musulmán, se hacían aún más precarias las probabilidades de que la entrada en la guerra del Imperio Otomano junto a las potencias centrales pudiera tener repercusiones significativas en el Sultanato ${ }^{55}$.

Otros aspectos que hacían relativamente restringido el papel de Marruecos en los designios y cálculos de la propaganda alemana sobre el mundo musulmán respondían a los propios intereses geoestratégicos alemanes, mucho más interesados en las regiones de Egipto y Oriente Medio (sobre todo en Mesopotamia, Siria y Líbano), que en el norte de África. Incluso en esta última región, las preferencias alemanas se dirigían hacia la Tripolitania y Argelia, en mayor medida que hacia Marruecos. Fuera cierto o no que, como afirmó después de la guerra el jefe de la inteligencia alemana en Oriente Medio —el aristócrata, banquero y diplomático Max von Oppenheim—, las actividades conspiratorias alemanas en el mundo musulmán no habían hecho sino dar "palos de ciego" durante todo el conflicto, parece evidente que Marruecos no ocupó un lugar prioritario en las mismas ${ }^{56}$.

Conocemos, en cualquier caso y por así decir, la arquitectura exterior de estas ambiciones en Marruecos: los representantes alemanes responsables de la coordinación de estas actividades conspiratorias desde la Península; las figuras intermediarias dispersas en diversas localidades andaluzas que servían de enlace con los agentes del otro lado del Estrecho y los agentes alemanes que operaban en la zona española (entre ellos, los hermanos Mannesmann y Albert Bartels). Del mismo modo, son conocidas las cantidades de dinero aproximadas que se invirtieron en la empresa y algunos envíos detallados de armamento y municiones; así como los jefes y las harkas que los recibieron y las actividades que supuestamente garantizaron con dichos apoyos. La documentación es abundante y, por lo que se refiere a Marruecos, confirma las figuras de Abd el-Malek —nieto del líder de la resistencia argelina Abd el-Kader_ - y de Abd el-Krim — padre del futuro caudillo de la rebelión rifeña — como dos figuras principales en la ofensiva germano-turca en el Rif, y la ciudad de Melilla como un centro importante del espionaje alemán en la zona oriental española. En la zona occidental, la actitud ambigua del Muley Ahmed el-Raisuni — caudillo, señor feudal y verdadera autoridad en la región de Yebala, en los alrededores de Tetuán — le permitió beneficiarse de los envíos de dinero y armas alemanes y, al mismo tiempo, mantener sus contactos con las autoridades españolas ${ }^{57}$.

\footnotetext{
${ }^{55}$ Lo que no fue obstáculo, como han recordado algunos autores, para que amplios sectores de la población local expresara su confianza en la victoria alemana y en la derrota de Francia. (BALFOUR, Deadly..., p.48). Recuérdese, por otra parte, que Moulay Youssef había declarado la guerra a Alemania, aliada de la Sublime Puerta.

56 “ein Schlag in Wasser". Véase Tilman LÜDKE, op. cit., p. 186 y pp. 196-203.

${ }^{57}$ Una visión general en Ron M. CARDEN, German Policy Towards Neutral Spain, 2 ed., Oxon, Routledge, 2014, Tilman LÜDKE, op. cit., pp. 196 y ss. y David MOTADEL, Islam and Nazi Germany's War. Cambridge, MA. Harvard University Press, 2014, pp. 13-70. La bibliografía sobre las actividades alemanas en Marruecos en estos años es muy abundante. Véanse las memorias del propio Bartels (Albert BARTELS, Fighting the French in Morocco. Londres, A. Rivers, 1932) y las obras de Edmund BURKE, “Moroccan Resistance, Pan-Islam and German War Strategies", Francia, 3 (1975), pp. 434-64 y C. R. PENNELL, Morocco..., pp. 181-182; De particular relevancia es el estudio de Dirk SASSE, Franzosen, Briten und Deutsche im Rifkrieg 1921-1926: Spekulanten und Sympathisanten, Deserteure und Hasardeure im Dienste Abdelkrims. Munich, 2006, pp. 21-30. Para las figuras de Abd el-Malek y de Abd el-Krim puede verse María Rosa de MADARIAGA, Abd el -Krim el Jatabi. La lucha por la independencia. Madrid, Alianza, 2009, pp. 117-72. Sobre el-Raisuni, uno de los más señalados jefes locales y una figura trascendental en la temprana dominación española en Marruecos, véase Carlos Federico TESSAINER Y TOMASICH, El Raisuni. Aliado y enemigo de España. Málaga, Algazara, 1998.
}

HISPANIA NOVA., 15 (2017), págs. 500-526 DOI: https://doi.org/10.20318/hn.2017.3499 
En mayor medida que revisar en detalle la multitud de tentativas, proyectos, promesas y acuerdos para el envío de dinero y la formación de harkas contra las tropas francesas que se llevaron a cabo en estos años $\longrightarrow$ y de los que el lector puede obtener información abundante en la bibliografía citada-, puede resultar más relevante hacer referencia aquí a otras áreas de investigación, también relacionadas con las actividades alemanas en Marruecos, que continúan aún en cierta penumbra. Parece inevitable subrayar que ha existido una tendencia a estudiar la influencia de la propaganda y las actividades alemanas en Marruecos durante la Gran Guerra desde la perspectiva de las autoridades coloniales francesas y españolas — en algunos casos interesadas en exagerar la importancia de las mismas $^{58}$ - en mayor medida que desde la percepción de las tribus del territorio. Sobre todo en lo que se refiere a las divisiones y tensiones internas que la propaganda alemana provocó en el Marruecos tribal, existen algunos aspectos que parecen haber sido relegados por la historiografía a los márgenes de la cuestión ${ }^{59}$. Éstos se revisarán aquí brevemente.

Uno de ellos se refiere al complejo equilibrio y dinámica interna de las tribus del Rif, en las cuales una multitud de factores aseguraba tanto la cohesión de las mismas como sus inevitables fracturas y tensiones. La influencia de la propaganda alemana en dichas relaciones (las disensiones internas de las tribus con respecto a las actividades alemas, las facciones que se crearon como resultado de las mismas) se haya aún tan sólo relativamente explorada. Por otra parte, estas reacciones localizadas ante las promesas y los envíos de dinero, material y armamento de los agentes alemanes, afectaron también al sistema colectivo de relaciones inter-tribales en el Rif, modificando su balance y su juego de alianzas y confrontaciones. Finalmente, las llamadas a la yihad del Califato turco contra las potencias de la Entente, encontraron en el Rif una variedad de respuestas de acuerdo con las diferentes prácticas y vivencias particulares de la fe islámica —influencia de imanes, proliferación de cofradías-, que añadieron mayor complejidad a este escenario. Según el parecer de algunos autores, particularmente antropólogos, estas tres dimensiones no han recibido la importancia que merecen en las valoraciones sobre la propaganda alemana en el Marruecos tribal durante la Gran Guerra. En definitiva, si parece posible presentar, de manera exhaustiva incluso, minuciosa evidencia de las actividades conspiratorias alemanas en la zona española, no parece serlo tanto valorar de manera precisa sus efectos sobre la dinámica y las relaciones entre las tribus del Rif $^{60}$.

En cualquier caso, de manera general y hasta donde parece posible presumir, las actividades alemanas no perturbaron decisivamente la tranquilidad reinante en la zona española durante los años

\footnotetext{
${ }^{58}$ Moshe Gershovich apunta que las dificultades para valorar el grado de influencia de las actividades alemanas en Marruecos se debe en buena medida a este factor (Moshe GERSHOVICH, op. cit., p. 106).

59 Samar ATTAR, Debunking the Myths of Colonization: The Arabs and Europe. Plymouth, University Press of America, 2010, pp. 2 y ss.

${ }^{60}$ Sobre estos debates, puede verse Ernest GELLNER, "Doctor and saint" y David M. HART, "Segmentary Systems and the role of the 'five fifth' in tribal Morocco", ambos en Akbar S. AHMED y David M. HART (eds.), Islam in Tribal Societies. From the Atlas to the Indus, London, Routledge and Kegan Paul, 1984, pp. 21-38 y pp. 66-105, respectivamente. Otras aportaciones en Ángeles RAMÍREZ y Bernabé LÓPEZ GARCÍA, Antropología y antropólogos en Marruecos: homenaje a David M. Hart. Barcelona, Bellaterra, 2002 y Mimoun AZIZA, La sociedad rifeña frente al Protectorado español de Marruecos (1912-1956). Barcelona, Bellaterra, 2003.
} 
de la guerra, al menos en su superficie ${ }^{61}$. A ello probablemente ayudó el hecho de que una de las primeras manifestaciones de la neutralidad española al otro lado del Estrecho fuera la suspensión de avances y campañas de envergadura y la limitación de las tareas militares a operaciones de policía y vigilancia, prioridades que, sin duda, contribuyeron a la general quietud y sosiego en el territorio ${ }^{62}$. Merece notarse, sin embargo, que objetivos tan señalados no supusieron la pasividad total de las unidades militares en Marruecos. Durante los años de la guerra, se realizaron incursiones y avances en las zonas fronterizas que, sin ser tan notables como los de las campañas de 1919, pusieron de manifiesto que no se desaprovecharían oportunidades para avanzar en el dominio del territorio ${ }^{63}$.

Por otra parte, parece evidente que las autoridades militares de Ceuta, Melilla y Larache (y, por supuesto, Tetuán), eran conscientes tanto de la presencia de agentes alemanes en la zona española como de sus tentativas para establecer contacto con las tribus del interior, con el fin de alimentar una posible sublevación contra la zona francesa. Existen pocas dudas a este respecto y, frecuentemente, los historiadores han valorado la actitud de las mismas como un ejemplo de la benevolencia con que tendían a verse estos empeños, e incluso como manifestación de tácita aquiescencia con los mismos, derivada de las predominantes tendencias germanófilas y anti-francesas en el Ejército de África ${ }^{64}$.

En realidad, hay muchas razones para apoyar esta versión de los acontecimientos y la documentación existente proporciona numerosas pruebas en favor de la misma. Particularmente interesante resulta la correspondencia entre el Alto Comisario Francisco Gómez Jordana y otros jefes militares del territorio, en la que se puso de manifiesto la exasperación y frustración que causaba al Alto Comisario esta actitud. Resultaba inconcebible para Gómez Jordana que, tanto los Comandantes Generales como sus subordinados, no acabaran de darse cuenta de que una disimulada simpatía hacia las actividades alemanas tan sólo podía causar trastornos y serias dificultades para la labor colonizadora española. Los ejemplos de estas advertencias son numerosos y, algunos de ellos, particularmente ilustrativos del conocimiento de estas conductas indolentes y de los motivos que posteriormente tendrían las autoridades francesas para denunciarlas. "Constantemente llegan a mí" —escribiría Gómez Jordana en julio de 1918, refiriéndose a la situación en la Comandancia de Melilla_ "reclamaciones del Gobierno que las recibe a su vez de países aliados respecto a complacencias con que en ese territorio se permite aprovisionamiento Abd- el-Malek. General Lyautey me ha escrito en el mismo sentido. Es menester extremar medidas recomendadas por mí reiteradamente particular" ${ }^{65}$.

Es interesante notar también, sin embargo, que las circunstancias generales en las que se encontraba inmersa la cadena de mando en el Ejército de África no facilitaban ni el control ni el efectivo cumplimiento de las órdenes del Alto Comisario en las distintas regiones de la zona española. Las

\footnotetext{
${ }^{61}$ De acuerdo con Gershovich, la influencia de Alemania en Marruecos durante el periodo fue "nominal" (Moshe GERSHOVICH, op. cit., p. 107). Evidentemente, un panorama muy diferente se dibujaba en lo relativo a la actitud de las tribus del Rif, que se haría evidente ante los futuros avances españoles.

${ }^{62}$ Según Pennell, Gómez Jordana reconoció en 1918 que nada se había hecho en Marruecos durante los cuatro años de guerra (C. R. PENNELL, Morocco p. 180).

${ }^{63}$ BALFOUR, Deadly..., pp. 46 y ss.

${ }^{64}$ Por ejemplo, C. R. PENNELL, A Country..., 53-56; María Rosa de MADARIAGA, Abd-El-Krim..., p. 125, y Gonzalo TERREROS CEBALLOS, op. cit., pp. 205-218.

${ }^{65}$ Francisco GÓMEZ JORDANA, "Correspondencia con Cte. Gral. de Melilla, Gral. Aizpuru”, Tetuán, 9 de Julio de 1918. Marruecos. Rollo 365, legajo 223, carpeta 11. AGMM.
} 
razones que pueden presentarse para explicar estas dificultades son variadas. Entre ellas, el estado precario de muchas unidades en lo relativo a material y armamento, la corrupción imperante en las mismas y el aletargamiento e inercia de muchos mandos en lo relativo a las instrucciones recibidas desde Tetuán, razones que figuraron de manera prominente en la correspondencia entre el Alto Comisario y Madrid, y entre éste y sus allegados.

Sorprende de algún modo leer las continuas amonestaciones del Alto Comisariado sobre aspectos variados y diversos del servicio militar en el Protectorado, que incluían desde la vedada caza de jabalíes hasta la apropiación indebida de materiales expropiados a los nativos para la construcción de instalaciones militares (o privadas). Corrupción, desaliño en los uniformes, ignorancia de instrucciones precisas para la formación y entrenamiento de los soldados (prácticas de tiro, duración de las marchas), uso de recursos colectivos en beneficio privado,... La colección de irregularidades y abusos en el modus vivendi de las unidades estacionadas en la zona de influencia española parecía abarcar todos los extremos. En algunos casos, alcanzaba cotas difícilmente superables, como el comercio de municiones entre los puestos avanzados y las cabilas circundantes, que, en ocasiones, las utilizaban contra estos últimos. La repetición y frecuencia de dichas advertencias y recomendaciones, en algunos casos con veladas amenazas, hacen suponer que el Alto Comisario Gómez Jordana era perfectamente consciente del aletargamiento y apatía del ejército bajo su mando, que no ocultó tampoco a sus superiores en Madrid. Cabe tan sólo imaginar qué modalidad de avances militares podían efectuarse en estas condiciones y los múltiples percances, imprevistos e infortunios que parecían destinados a producirse durante los mismos. Es interesante resaltar, a este respecto, que Gómez Jordana no dejó de lamentar el escaso equipamiento y recursos de que se estaba dotando al Ejército de África, y se quejó amargamente de ello en su correspondencia con Madrid. Sin embargo, sus quebraderos de cabeza y sus críticas parecían más orientados al pobre uso que se hacían de los mismos y, sobre todo, al escaso espíritu militar existente entre muchos oficiales y suboficiales de los más variados cuerpos y unidades ${ }^{66}$.

En realidad, no era tan sólo el Alto Comisario el que percibía estas lacras profundas en el Ejército de África. Numerosos observadores civiles lamentaban también este estado de cosas y, en particular, la posición marginal y subordinada en que se mantenía a las autoridades civiles en la administración de la zona española. A sus críticas contra la corrupción del elemento militar se unían así otras consideraciones que subrayaban su falta de preparación para la tarea colonizadora: su arrogancia frente a la administración civil (a la que en último término debían su autoridad), su escaso conocimiento de la realidad marroquí (lengua, tradiciones, costumbres, modos de vida) y su preponderancia y desprecio habitual en su trato con las tribus y cabilas $^{67}$. Algunos soldados, incluso, se atreverían a ir aún más lejos en estas denuncias, informando a la Comandante General de Melilla, por ejemplo, de

\footnotetext{
${ }^{66}$ La lista de documentos es larga. Entre los más relevantes: Francisco GÓMEZ JORDANA, “Correspondencia con Ccia. Gral. de Ceuta", Tetuán, 11 de Enero de 1916 y 6 de Junio de 1916. Marruecos. Rollo 927, legajo 13. AGMM. Véase también BALFOUR, Deadly..., pp. 46-47. Para un análisis de otras carencias de la organización administrativa del Protectorado, véase, José Luis VILLANOVA VALERO, El protectorado de España en Marruecos. Organización política y territorial. Barcelona, Bellaterra, 2004.

${ }^{67}$ La carta de Manuel FERRER, juez de paz en Tetuán, dirigida al ministerio de Gobernación el 24 de septiembre de 1915, es un buen ejemplo. Marruecos. Legajo 251, carpeta 11. FAMM.
} 
humillaciones y abusos a los que los soldados de la Comandancia frecuentemente sometían a aquellos supuestamente protegidos por la acción española ${ }^{68}$.

Por lo demás, un buen número de representantes extranjeros, sobre todo ingleses y franceses, deploraron también con frecuencia la crónica ineptitud de los mandos españoles y su ignorancia de los más elementales principios militares. Buena parte de ellos consideraba que, en realidad, el ejército colonial estaba llevando a cabo en Marruecos la misma estrategia que había desarrollado en Cuba —uso de blocaos y puestos fronterizos alejados unos de otros, ausencia de comunicaciones fiables, independencia de acción de los jefes intermedios con respecto al criterio de las altas autoridades militares - con resultados que podían ser previsibles ${ }^{69}$.

En definitiva, por tanto, puede decirse que la generalidad de los oficiales españoles adoptó una actitud benevolente y de pretendida ignorancia con respecto a las actividades alemanas en la zona de influencia española, que, en muchos casos, exasperó al Alto Comisario Gómez Jordana. Por otra parte, sin embargo, debe tenerse en cuenta también que eran limitados los medios a su disposición para hacer respetar sus órdenes, no sólo en lo relativo a las actividades alemanas, sino en la propia administración del territorio. La corrupción y apatía reinante en muchas unidades del Ejército de África que, junto con carencias fundamentales de preparación, material y equipamiento, dificultaban la acción colonial española en Marruecos, limitaron también, finalmente, la vigilancia sobre las actividades alemanas y sus posibles repercusiones sobre las tribus del territorio.

\section{LAS SEMILLAS DE LA DISCORDIA}

Particularmente receptivas a estas conductas y proclives a denunciarlas abiertamente, las autoridades militares francesas no dejaron de señalar numerosos ejemplos de tendenciosidad y parcialidad entre los jefes y mandos del Ejército de África y pruebas flagrantes de su pasividad e inacción, que desmentían la pretendida neutralidad de la zona española. La libertad de que gozaban los agentes alemanes en sus desplazamientos por la misma; la facilidad con que podían establecer contacto con los cabecillas locales — sobre todo Abd el-Malek, buscado por traición en la zona francesa-; los frecuentes envíos de instrucciones, fondos, municiones y armamento; la presencia en territorio rifeño de "asesores" alemanes $y$, finalmente, los disturbios crecientes en los puestos avanzados del Protectorado francés, se mencionaron repetidamente en los informes enviados por el Residente General desde Rabat. Las recriminaciones del Mariscal Lyautey, como era de esperar, se prolongaron a lo largo de todo el conflicto. El Residente General francés censuró repetidamente, y de un modo cada vez más virulento, la dejadez, desidia y apatía de las autoridades militares españolas con respecto a las actividades alemanas, y su inoperancia, culpable ignorancia y, en algunos casos, connivencia con las

\footnotetext{
${ }^{68}$ Aproximadamente un año antes del comienzo de la guerra, el cabo Francisco Díaz Barrio, estacionado en Melilla, relataba lo siguiente: "Sucede todos los días cientos de veces que mis compañeros de todos los Cuerpos y Armas al reunirse con moros, se complacen en restregarles cortezas de tocino por los labios; quererlos hacer beber vino, decirles que les traigan a sus mujeres; tratarles con desprecio y dureza, echándolos a empujones de las cantinas y otras mil cosas, todas ellas consecuencia de un odio que, aunque justo, contrarresta el buen deseo de V.E." Informe al General en Jefe. 3 de Febrero de 1913. Marruecos, Rollo 266, legajo 117, carpeta 4. AGMM.

${ }^{69}$ Cónsul general británico en Tánger, Mr. WHITE, 20 de Marzo de 1915. Morocco, Political Correspondence, leg. 371/2411. PRO FO. A ellos se sumó el representante de la Delegación estadounidense en Tánger, Maxwell BLAKE, unos meses antes de la guerra: "Report", Tánger, 19 de Julio de 1913, Morocco (1910-1929), Political Notes, 1910, Microfilm, Reel 3, Files 881.000/549. National Archives and Records Administration (NARA).
} 
mismas. En último término, las responsabilizó de la situación creada en la zona española y también de las consecuencias desestabilizadoras que se estaban produciendo en el Protectorado francés ${ }^{70}$.

Lyautey dirigió estas reprobaciones, principalmente, a su propio gobierno, del que esperaba una tajante reacción diplomática que planteara de manera incontrovertible y exigiera puntualmente a España el cumplimiento estricto de sus deberes internacionales en la zona de influencia en Marruecos. En algunas ocasiones, sin embargo, durante esporádicas visitas a Francia y obligadas escalas en España, tuvo también la oportunidad de manifestar su descontento y frustración tanto al rey Alfonso XIII como a los responsables de la política exterior española. Años después, y recordando con amargura estas conversaciones, el Mariscal deploraría el cinismo y las excusas pueriles que encontraron sus reclamaciones en los mandatarios españoles ${ }^{71}$.

Las impresiones de Lyautey, aunque quizá exageradas, tenían claro fundamento. Abundantes documentos oficiales parecen confirmar que, en efecto, el gobierno español era perfectamente consciente de estas circunstancias y de las fricciones que estaban creando con las autoridades francesas. En conversaciones mantenidas en 1916 con el embajador británico en España, Mr. Hardinge, el conde de Romanones, jefe de gobierno por aquel entonces, admitió que el gobierno de Madrid se encontraba en una situación de impotencia en lo que se refería a la zona de influencia española en Marruecos, y que sus órdenes para que se defendiera de manera rigurosa la neutralidad española encontraban muchas dificultades para cumplirse, sobre todo por parte de la autoridad militar ${ }^{72}$. Fuera cierta o no esta indefensión, o simplemente un subterfugio para excusar la responsabilidad del gobierno en la materia, sí parece probable que los gabinetes que se sucedieron en Madrid durante los años de la Gran Guerra (siete de ellos en total), se vieran inmersos en circunstancias similares con respecto a la política colonial ${ }^{73}$. Que ello se debiera, como han afirmado algunos autores, al hecho de que Marruecos se hubiera convertido ya en una suerte de feudo militar, en el que la creciente tendencia del Ejército español a intervenir en la esfera pública — palpable desde comienzos del siglo XX-, hubiera encontrado ya un espacio privilegiado para asentar aspiraciones militaristas, es, sin duda, muy posible ${ }^{74}$. Otras explicaciones apuntarían a la endeblez crónica de la política colonial española, al desconocimiento generalizado de la realidad marroquí por parte de los representantes civiles y a la ausencia de un proyecto colonial coherente como causa última de esta situación, un vacío de dirección y una

\footnotetext{
${ }^{70}$ Maréchal LYAUTEY, "Télégramme a Mr. Delcassé, Ministre des Affaires Étrangères”, Rabat, 8 Mayo 1915. Maroc, 1917-1940, leg. 1652. MAEDI. Sobre la ansiedad de los franceses en 1917 y 1918, véase C. R. PENNELL, Morocco..., p. 182.

${ }^{71}$ Maréchal LYAUTEY, “Correspondance avec Lt. Col. Cuverville. Attaché militaire en Espagne”, Rabat, 4 de Marzo de 1924. Maroc, 1917-1940, leg. 197. MAEDI.

72 Arthur H. HARDINGE, San Sebastián, 21 de Septiembre de 1916. Morocco, Political Correspondence, Leg. 371/2712. PRO FO.

${ }^{73}$ Dicha situación, por otra parte, se asemejaba hasta cierto punto a la que sufría y experimentaba el mismo Alto Comisario con respecto a las Comandancias Generales de Ceuta, Melilla y Larache. Véase José Luis VILLANUEVA VALERO, El protectorado..., pp. 240-323.

74 El tema fue largamente debatido en los años 80 (Cardona, Ballbé, Seco Serrano, Lleixá, Núñez Florencio) y recientemente visitado por María GÁRATE BAJO, "El ejército colonial español en Marruecos. Distintas percepciones del Protectorado", Revista de Historia Actual, 8 (2010), pp. 102 y ss.
} 
ambigüedad hasta cierto punto calculada en muchos gobiernos de la Restauración (interesados en esquivar la responsabilidad de la misma), que el Ejército fácilmente aprovechó en su propio interés ${ }^{75}$.

En cualquier caso, es indudable que la situación de la zona española creó enormes dificultades para el Mariscal Lyautey, que, por una parte, debía asegurar la estabilidad del Protectorado francés y, por otra, responder a las demandas cada vez más insistentes de su propio gobierno, y enviar al continente un número cada vez más crecido de batallones. Es bien sabido que la estrategia de Lyautey para resolver esta difícil tesitura no consistió en la retirada de tropas de los puestos avanzados franceses, sino, por el contrario, en el mantenimiento de los mismos y, simultáneamente, en el vaciamiento progresivo de los territorios ya dominados y más largamente mantenidos bajo control francés. Dicha estrategia, que él denominó una "coraza protectora externa" era, sin duda, arriesgada, como hicieron notar varios representantes gubernamentales, y ello obligó a Lyautey a defenderla con ímpetu y vehemencia ${ }^{76}$. En su opinión, la clave para mantener el dominio francés en el Protectorado durante la guerra se fundamentaba en una idea relativamente simple: ofrecer a los marroquíes una impresión de continuidad y estabilidad, rechazar medidas apresuradas y consolidar la fortaleza y el prestigio de Francia a los ojos de la población local, incluso si estos distaban de contar con pilares verdaderamente sólidos ${ }^{77}$. El acierto en los continuos desplazamientos de las unidades volantes que Ilevaban a cabo operaciones de policía en la zona avanzada y la eficacia de los servicios de inteligencia y propaganda franceses aseguraron la viabilidad de dicha táctica durante todo el conflicto.

Los numerosos problemas que la situación creó a Lyautey, sin embargo, son difíciles de ignorar. A diferencia de la aparente tranquilidad de la zona española, la actividad militar en el Protectorado francés conoció menos descanso en estos años, quizá por encontrarse ya comprometida en diversos frentes de los que no podía desembarazarse sin causar mayores dificultades de las que pretendía evitar. Lyautey, por tanto, centró sus objetivos inmediatos en finalizar los avances ya iniciados en la región del Atlas y completar operaciones de reconocimiento que finalmente estabilizaran dicha "coraza exterior", que él aspiraba a mantener como línea última de contacto y frontera estable entre la dominación francesa y las tribus aún insumisas a la misma. El hecho de que esta zona de seguridad se mantuviera más o menos firme e impenetrable en aquellos años no debe hacer olvidar las dificultades que entrañó la empresa ni los fracasos militares que puntuaron la misma ${ }^{78}$.

En realidad, y pese a las apariencias, las fuerzas coloniales francesas y el propio Lyautey se encontraban en una posición extremadamente delicada, sobre todo por el conocimiento, en diversas ocasiones compartido por el Residente General con sus superiores de París, de que cualquier fisura en la línea avanzada no encontraría en la retaguardia sino un número muy disminuido de fuerzas para hacerla frente. El efecto que, en esta situación, pudieran causar las noticias de las actividades alemanas en la zona española y la aparente indiferencia de las autoridades españolas ante las mismas, ambas ampliamente documentadas por los servicios de inteligencia franceses, no debe desdeñarse. A pesar de

\footnotetext{
${ }^{75}$ Quizás esta visión resulte más interesante y certera, y ha sido apuntada por Carolyn P. BOYD, op. cit., p. 17; Sebastian BALFOUR, Deadly, pp. 46-51 y Moshe GERSHOVICH, op. cit., pp. 103-106.

${ }^{76}$ Moshe GERSHOVICH, op. cit., p. 102.

77 Maréchal LYAUTEY, “Correspondance avec Mr. Painlevé, Ministre de la Guerre”, Rabat, 24 de Julio de 1917. Maroc, Cabinet Militaire, CMC4, Centre des Archives Diplomatiques de Nantes (CADN).

${ }^{78}$ Por ejemplo, en la posición de Tafilalet en 1917 (Moshe GERSHOVICH, op. cit., pp. 107-11).
} 
su tendencia ocasional a los excesos melodramáticos, Lyautey no pareció, en este caso, exagerar las cosas cuando aseguraba que la zona española se había convertido en una parte del frente enemigo ${ }^{79}$.

La inacción de las autoridades españolas y sus tibias excusas provocaron en Lyautey una exasperación profunda y creciente, sobre todo por su convencimiento, expresado en diversas ocasiones, de que el castillo de naipes erigido por la administración francesa en Marruecos podía venirse abajo en cualquier momento. En fechas tan tardías como junio de 1918 -algo que sorprende hasta cierto punto al investigador-, Lyautey consideraba poco menos que inevitable e inminente un derrumbamiento parcial de la autoridad francesa en Marruecos, debido al estado de agitación existente entre las tribus, al que no eran ajenas las actividades alemanas en la zona española ${ }^{80}$. Aunque éste no se produjera finalmente y la guerra finalizara tan sólo meses más tarde, no debe minusvalorarse la huella duradera, el resentimiento soterrado y la impronta de recelo y rencor casi insuperable que estos años dejaron en el Mariscal y el efecto que tendría en las futuras relaciones con las autoridades españolas. Lyautey no dudaría en calificar como un "acto de traición" la actitud de España en Marruecos durante la guerra, y tampoco vacilaría en declarar que su gobierno debía exigir al gobierno español compensación y reparación por la sangre francesa vertida en el Protectorado en dichos años ${ }^{81}$. La "fobia anti-española" de Lyautey, en palabras de uno de sus más atentos estudiosos, y su resistencia en años venideros a cualquier atisbo de cooperación con las autoridades españolas - incluso en circunstancias que parecían claramente aconsejarla, como en las últimas etapas de la guerra del Rif (1921-1926) debió mucho a sus experiencias durante la guerra, una suerte de travesía del desierto que, una vez finalizada, hizo poco menos que imposible la colaboración entre Francia y España en Marruecos ${ }^{82}$. Como ya había advertido, por otra parte, el Alto Comisario español Gómez Jordana, España era quien peor parada debía salir de dicha situación ${ }^{83}$.

En definitiva, las iniciativas alemanas durante los años de la guerra, indudablemente favorecidas por la inercia y la pasividad española, ofrecieron a las tribus y cabilas de la zona española una multiplicidad de opciones y más recursos potenciales a la hora de establecer su posición relativa con respecto a otras tribus y también de definir su postura tanto con respecto a las autoridades españolas como a las francesas. Este equilibrio frágil, que varios autores han interpretado como prueba de doblez, pragmatismo y ambigüedad entre los jefes locales ante la miopía de la administración española, podría también entenderse como una estrategia de supervivencia — tan legítima como cualquier otra-, favorecida por las fisuras entre las potencias europeas y que intentó extraer los mayores beneficios de

\footnotetext{
79 Maréchal LYAUTEY, “Correspondance avec Mr. Painlevé, Ministre de la Guerre”, Rabat, 5 de Noviembre de 1918. Maroc, Cabinet Militaire, CMC6. CADN.

80 Maréchal LYAUTEY, “Correspondance avec l'Ambassadeur de France à Madrid”, Rabat, 9 de Junio de 1918. Maroc, Cabinet Militaire, CMC5. CADN.

${ }^{81}$ Maréchal LYAUTEY, “Télégramme a Mr. Pichon, Ministre des Affaires Étrangères”, Rabat, 9 de Marzo de 1918. Maroc, 1917-1940, leg. 186. MAEDI.

82 Daniel RIVET, Lyautey et l'institution du Protectorat Français au Maroc, 1912-1925. Paris, L'Harmattan, 1988, vol. III, p. 273.

${ }^{83}$ Francisco GÓMEZ JORDANA, "Correspondencia con el Gral. Milans del Bosch", Tetuán, 21 de Septiembre de 1915. Marruecos. Rollo 357, legajo 214, carpeta 3. AGMM.
} 
las mismas ${ }^{84}$. La idea de que las promesas alemanas espolearon las tendencias anárquicas y rebeldes siempre latentes entre las tribus del Rif y sus deseos de sacudirse el yugo colonial —que se dirigirían contra España en mayor medida que contra Francia en los años 20-, puede necesitar completarse, por tanto, con una referencia a las reacciones enteramente pragmáticas de estas últimas. Sólo en función de las ventajas obtenidas por los pagos y los envíos de armas y municiones $\longrightarrow$ y no por ninguna supuesta confianza, sujeción o connivencia con las aspiraciones alemanas - se llevaron a cabo acciones que favorecieron estas últimas, de manera directa o indirecta ${ }^{85}$. La postura ambigua y contradictoria de España en estas circunstancias, no hizo sino probablemente confirmar este modus operandi de la resistencia entre las tribus no sometidas de la zona española. En lo relativo a la administración francesa, como se ha visto, la situación se convirtió en un motivo de ansiedad e inquietud constante durante la guerra y, finalmente, en prueba irrefutable de la incompetencia de España como socio colonial.

\section{CONCLUSIONES}

Podría decirse, con el fin de concluir estas páginas, que la zona de influencia de España en Marruecos experimentó, por una parte y de manera leve, algunas de las controversias despertadas por la Gran Guerra en la Península, y, por otra y de manera más profunda, otras ramificaciones del conflicto. Entre las primeras, podrían señalarse la división entre aliadófilos y germanófilos y los sucesos revolucionarios de 1917, que apenas encontraron eco, o tan sólo reverberaciones lejanas, más allá del Estrecho. Entre las segundas, el pulso entre junteros y africanistas, de una manera también más matizada que en la Península, y, sobre todo, las repercusiones de la propaganda alemana, verdaderamente significativas para el futuro de la colonización española.

El debate entre aliadófilos y germanófilos se vio limitado en el Protectorado español por una serie de circunstancias que incluían la escasa circulación de medios periodísticos y de opinión, la abrumadora presencia del elemento militar en el territorio y el incipiente desarrollo de la sociedad civil. La uniformización de un criterio generalmente germanófilo tanto entre las autoridades militares como entre los escasos representantes civiles en Marruecos se vio también favorecida, indirectamente, por el relativo interés en la cuestión por parte de la población española residente en el Protectorado, en buena parte iletrada y dispersa por el territorio (excepto en Tetuán y Larache). Si es cierto que Marruecos se convirtió en un punto de referencia en el intenso debate peninsular entre los partidarios de Alemania, los defensores la Entente y los escasos pacifistas que existían en España, también lo fue, irónicamente, que, en el mismo Protectorado, las discusiones sobre la orientación de la política exterior española pasaron prácticamente desapercibidas, y enmudecieron en un contexto mayoritariamente germanófilo.

Otras derivaciones de la Primera Guerra Mundial, que podrían simbolizarse en los sucesos del verano revolucionario de 1917, también tuvieron limitadas repercusiones en Marruecos. Quizás su ejemplo más relevante, la huelga general revolucionaria decretada en julio de 1917, pasó prácticamente

\footnotetext{
${ }^{84}$ Balfour en el primer caso (Sebastian BALFOUR, Deadly, p. 48) y Ayache, en mayor profundidad y refieriéndose a Abd el Krim y el Raisuni, en el segundo (Germain AYACHE, op. cit., pp. 227-287).

${ }^{85}$ Balfour afirma que las actividades alemanas ayudaron a acrecentar la resistencia de las cabilas contra la autoridad española (Sebastian BALFOUR, Deadly, p. 48), mientras que Germain Ayache considera que las tribus de la zona española simplemente siguieron estrategias de superviviencia tradicionales (Germain AYACHE, op. cit., pp. 227-254).
}

HISPANIA NOVA., 15 (2017), págs. 500-526 DOI: https://doi.org/10.20318/hn.2017.3499 
inadvertida en la zona española, tanto por el férreo control de la censura militar —en condiciones que permitían ejercitarla con una mayor eficacia que en la Península-, como por la inexistencia de organizaciones sindicales o partidos políticos que hubieran podido encauzar sus reivindicaciones.

Sí podría asegurarse, en cambio, que las polémicas sobre las reformas militares que surgieron y acompañaron los años de la guerra en España, y en las que Marruecos figuró de manera destacada, despertaron el interés y la atención entre los mandos (oficiales y suboficiales) del Ejército de África. El predominio de una tendencia con respecto la actitud de España en la guerra y la deseada marcha de la misma, en este caso germanófila, no fue obstáculo para que se manifestaran diferencias y divisiones en relación con la dirección y el sentido de dichas reformas que, en último término, pretendían equiparar al Ejército español a otros ejércitos europeos. Por utilizar los términos habituales asociados con esta división, la opinión "africanista", tan sólo representada por algunas unidades de reciente creación en el Ejército de África, contaba, sin embargo, con simpatías entre la élite militar y los altos mandos en la Península, algunos de los cuales se habían beneficiado en sus carreras de ascensos y condecoraciones obtenidos en Marruecos. La opinión "juntera", hasta donde es dado valorarla, se mostraba predominante en los batallones peninsulares destinados a Marruecos, en los que la mayoría de oficiales y suboficiales tan sólo esperaban el término de su servicio para poder regresar a España. Estas divisiones, muy condicionadas por los acontecimientos de la Península, se moderaron (aunque no desaparecieron) cuando se implantó finalmente en Marruecos un modelo de actuación colonial más cercano a las pretensiones junteras, que se concretó en la protección de un estricto orden jerárquico de promociones y en la progresiva afirmación de un carácter quietista y burocrático en la acción militar, alejado de previos aventurismos coloniales. La reforma militar de 1918, en la que se confirmaron estas prioridades, dejó sin solucionar, sin embargo, los problemas más graves del ejército en Marruecos (carencias de recursos, material y equipamiento, deficiente instrucción de las unidades, corrupción extendida entre mandos y subordinados) y acabaría sancionando una mentalidad y una idiosincrasia escasamente adaptadas a la realidad colonial.

Desde un contexto internacional, las aspiraciones de la propaganda alemana de subvertir el orden y la dominación imperial de las potencias de la Entente en el mundo musulmán —estimulada por la entrada del Imperio Otomano en la guerra al lado de las Potencias Centrales-, situó también a Marruecos en la órbita de sus estrategias y actividades. Ciertamente, por motivos históricos y religiosos, el Sultanato marroquí era más refractario a los designios y liderazgo del Califato Turco que otras regiones del norte de África, y no debe sorprender, por tanto, que las llamadas a la guerra santa proclamadas en Constantinopla tuvieran una escasa resonancia en el territorio (como también ocurrió en otros dominios del mundo musulmán). También es cierto, sin embargo, que la presencia, la financiación y los envíos de armas y municiones en la zona española, canalizados a través de los agentes alemanes, despertaron la ambición de diversos jefes locales, que utilizaron dichos recursos de una manera eminentemente pragmática.

Más relevantes fueron las consecuencias que se derivaron de la propaganda y actividades alemanas y, sobre todo, de la tibia respuesta de las autoridades españolas ante las mismas, para el futuro de la colonización española en Marruecos. Las maniobras alemanas crearon enormes dilemas a la administración francesa e incontables inquietudes para el mariscal Lyautey que, en razón de las mismas, acabó convenciéndose de la inutilidad de intentar establecer relaciones amistosas con España en Marruecos y, por el contrario, de la necesidad de mantener una estrecha vigilancia sobre la zona española, percibida más como una amenaza para los intereses franceses que como un territorio de 
entendimiento entre socios coloniales. De este desencanto y resentimiento emergería una renovada rivalidad y desdén hacia las autoridades coloniales españolas, que no haría sino agravar las precarias circunstancias de la presencia de España al otro lado del Estrecho, mucho más necesitada de la colaboración francesa que ésta de la española. En este contexto de recelo y desconfianza, puede sugerirse que la reanudación de operaciones militares en 1919 y las dificultades posteriores creadas por la guerra del Rif, cuya prolongación acabaría finalmente asestando el golpe de gracia al régimen de la Restauración, no fueron sino expresión clara de las condiciones creadas en el Protectorado marroquí durante la Primera Guerra Mundial. 